\title{
COMPLICATIONS OF TRANSPLANTATION
}

\author{
Charles W. Putnam \\ Thomas E. Starzl
}

During the last decade whole-organ transplantation, particularly of the kidney, has become increasingly established as a sophisticated kind of patient service. As a consequence, transplantation centers have been started in almost every part of the world. In the United States there are few major medical schools that do not have the capability of carrying out transplantation of at least the kidney. Medical students, house officers, and faculty members are being called upon increasingly to participate directly or indirectly in the management of the resulting complications and problems.

It is the purpose of this chapter to discuss the many things that can go wrong after whole-organ transplantation and to indicate what may be done of a corrective nature. As will become evident, the complications stem from one or more of the following etiologic factors: (1) preexisting organ failure; (2) technical imperfections in the performance of transplantation; (3) inability to control rejection of the new organ; (4) side effects of immunosuppressive agents given to prevent rejection; and (5) other coincidental disease not related either to organ failure or to immunosuppression.

\section{SPECIAL ANESTHETIC CONSIDERATIONS}

With transplantation of either the kidney or liver, the patient enters the operation with a well defined loss of certain metabolic pathways by which anesthetic agents are detoxified or excreted or both.

\section{Renal Transplantation}

The anesthetic complications facing renal homograft recipients during their transplantations are the consequence of uremia. If homograft function is prompt and adequate, many of the potential problems such as fluid overload or hyperkalemia will be speedily relieved. However, not all homografts achieve a remedial level of function intraoperatively, and the safest approach to the anesthetic management of these patients is to assume that prompt urine excretion will not occur.

There are no specific contraindications to any of the common inhalant anesthetic agents. Considerable care must be exercised in the choice and administration of muscle relaxants, however. In 1964, Virtue ${ }^{87}$ cau-

Charles W. Putnam was born in Massachusetts and was elected to Alpha Omega Alpha at Northwestern University Medical School. He served his internship and residency at the University of Colorado Medical Center, and was awarded a USPHS Post Doctorate Surgical Traineeship. His experience in transplantation is reflected in his extensive publications in this field of research and practice.

Thomas E. Starzl was born in lowa, and attended Westminster College. He received both the M.D. and Ph.D. degrees from Northwestern University, where he was elected to Alpha Omega Alpha. Following internship and residency training at the Johns Hopkins Hospital and the University of Miami, he was named a Markle Scholar in Medical Science. An early worker in the newly applied clinical science of tissue transplantation, he is universally recognized as a world leader in organ transplantation in man. Having established the University of Colorado as a mecca for those interested in the art and science of organ transfer, Dr. Starzl is now Professor and Chairman of the Department of Surgery in that institution. 
TABLE 1 INCIDENCE OF PROLONGED MUSCLE PARALYSIS*

\begin{tabular}{|c|c|c|c|c|}
\hline Muscle Relaxant Drug & $\begin{array}{l}\text { Number } \\
\text { of Patients }\end{array}$ & $\begin{array}{l}\text { Number with } \\
\text { Prolonged Weakness }\end{array}$ & Percent & Significance \\
\hline Gallamine & 15 & 3 & 20 & \multirow[b]{2}{*}{$\mathrm{p}=<0.01$} \\
\hline d-Tubocurarine & 191 & 7 & 3.6 & \\
\hline Total & 206 & 10) & 4.8 & (of all cases) \\
\hline
\end{tabular}

*From Aldrete, J. A., Daniel, W., O’Higgins, J. W., Homatas, J., and Starzl, T. E.: Analysis of Anesthetic-Related Morbidity in Human Recipients of Renal Homografts. Anesth. E Analg., 50:321, 1971.

tioned against the use of the depolarizing agent succinylcholine in recently dialyzed patients, in whom hepatic pseudocholinesterase, upon which succinylcholine inactivation depends, may sometimes be nearly absent. Although Sarmina et al ${ }^{80}$ have utilized succinylcholine in their recipients without incident, our anesthesiologists generally prefer to limit its use to induction, particularly if the patient has any evidence of hepatic insufficiency or hyperkalemia.

Prolonged muscle paralysis following successful transplant procedures was observed by Aldrete et al. in 10 (4.8 per cent) of 206 patients who received the nondepolarizing agents gallamine or d-tubocurarine (Table 1) for muscle relaxation. ${ }^{1}$ In addition to decreased muscle strength, respiratory function was inadequate in these patients and prolonged ventilatory support was required. The complication occurred significantly more frequently with gallamine than with d-tubocurarine. With either agent, the paralysis was not uniformly prevented by the administration of appropriate doses of anticholinesterase-type drugs. ${ }^{1}$ It is hardly surprising that this problem does occur, since gallamine in normal animals and man is excreted almost entirely by the kidney and d-tubocurarine is removed by a renal pathway at about a 90 per cent level.

In renal recipients, continuous electrocardiographic surveillance intraoperatively is essential to detect and treat cardiac arrhythmias before potentially lethal conduction defects supervene. Most such arrhythmias are directly related to disordered potassium balance. Of particular concern are preoperative serum potassium concentrations above $6 \mathrm{mEq}$. per liter or below $2.5 \mathrm{mEq}$. per liter. Attention should be directed to the serum potassium concentration before the final pretransplantation dialysis. If this value exceeds $6 \mathrm{mEq}$. per liter, it may be lowered temporarily by a single hemodialysis but a rebound hyperkalemia will frequently occur intraoperatively, as has been emphasized by Aldrete. ${ }^{2}$

A fall of 25 per cent or more of the systolic blood pressure is common during renal transplantation. ${ }^{1}$ Since most recipients enter the operating room hypertensive, such a decline is rarely of clinical importance. In actuality, it frequently signifies a restoration toward normal physiology by virtue of removal of the diseased kidneys and the provision of adequate renal function.

Chronic anemia also is a nearly universal preoperative finding and need not cause concern. Patients with uremia tolerate this condition well and preparatory transfusion is usually not indicated. In fact, preoperative transfusions may precipitate cardiac failure since a compensatory increase in plasma volume has usually already occurred. ${ }^{29}$ Instead, blood loss is replaced volumetrically during the transplantation with fresh packed red cells.

Aldrete has described intraoperative hyperpyrexia in a few cases of renal homotransplantation. The explanation for this complication has not been defined, although it may have been related to the prior administration of heterologous antilymphocyte globulin (ALG). In any case, it is important to monitor the intraoperative body temperature.

\section{Hepatic Transplantation}

With transplantation of the kidney, pharmacologic considerations must take into account the loss of a renal excretory pathway. 
With hepatic replacement the problem is infinitely more complex since so many drugs commonly in anesthetic use are either processed in some way or other by the liver or else have the capability of injuring the liver.

In addition, the liver operations tend to be long and bloody. Finally, with liver replacement (orthotopic transplantation) a major hemodynamic insult is incurred intraoperatively when the inferior vena cava and portal vein are temporarily occluded during the anhepatic phase while the new organ is being sutured in place. Pappas et al ${ }^{61}$ have shown that the cardiac output during this critical time may be reduced to onehalf or less of the prior state.

The complex anesthetic management problems of liver transplantation were worked out and described in detail by $\mathrm{Al}$ drete. ${ }^{88}$ The essentials for success include extensive monitoring of such diverse measurements as arterial and central venous pressures, electrocardiogram, urine output, and blood $\mathrm{pH}$, electrolytes, glucose, and blood gases. There must be provision for multiple intravenous inlets. When possible, Aldrete has preferred inhalation anesthesia with fluoroxene added to a nitrous oxideoxygen mixture and combined with muscle relaxants as needed.

\section{Other Organs}

For heart, pancreatic, and lung transplantation, there have not been such specific problems of drug detoxification.

\section{TECHNICAL COMPLICATIONS}

Errors in technique during the performance of renal or hepatic transplantation have made substantial contributions to the post-transplantation morbidity and mortality. Because of the obviously greater technical complexity of hepatic transplantation, technical complications have been and continue to be more frequent after this procedure than after renal transplantation. Moreover, with either procedure a technical error that in the ordinary surgical setting might be of little or no consequence may, in the face of immunosuppression, prove to be a clinically devastating or fatal one. For this reason, every effort must be made to achieve an anatomically and physiologically acceptable result at the time of surgery.

\section{Renal Transplantation}

The techniques used in the construction of the vascular anastomoses in renal transplantation have been well standardized, ${ }^{87}$ and it is extremely unusual to encounter vascular problems postoperatively. For example, in our first 64 cases of renal transplantation, there was only one case of arterial thrombosis and none of venous occlusion. Since that time, there have been instances of complications related to either vascular anastomosis but those leading to loss of the organ have been uncommon.

From time to time, however, in the course of revascularization, the anatomic situation of the donated kidney has been such that it has been impossible to completely revascularize it. Most frequently, a small polar arterial branch must be sacrificed in the course of donor nephrectomy or else it proves to be too tiny for successful reanastomosis. The consequence of accepting incomplete revascularization is the production of a regional infarct which, in certain instances, may be as large as one-third of the kidney mass. In our experience the only adverse effects of even a large infarct have been transient hypertension and early postoperative hematuria.

In contrast to vascular problems, urinary tract complications have been encountered frequently. Several of the leading centers in renal transplantation have extensively reviewed their experiences with this kind of complication. ${ }^{47}, 48,60,75,91$ However, for the purposes of this discussion, we have chosen as illustrative material a review of 216 consecutive patients from our series. ${ }^{91}$

In these 216 recipients, 234 kidneys were transplanted. In 178 instances, urinary drainage was reconstituted with ureteroneocystostomy as depicted in Figure 1. The urinary tracts of the other 55 kidneys were reconstructed with ureteroureterostomies (Fig. 2). In most instances, this latter procedure was performed even though ureteroneocystostomy was technically feasible. However, in a minority, ureteroureterostomy was performed either because the homograft ureter was too short to reach the (Text continued on page 748.) 

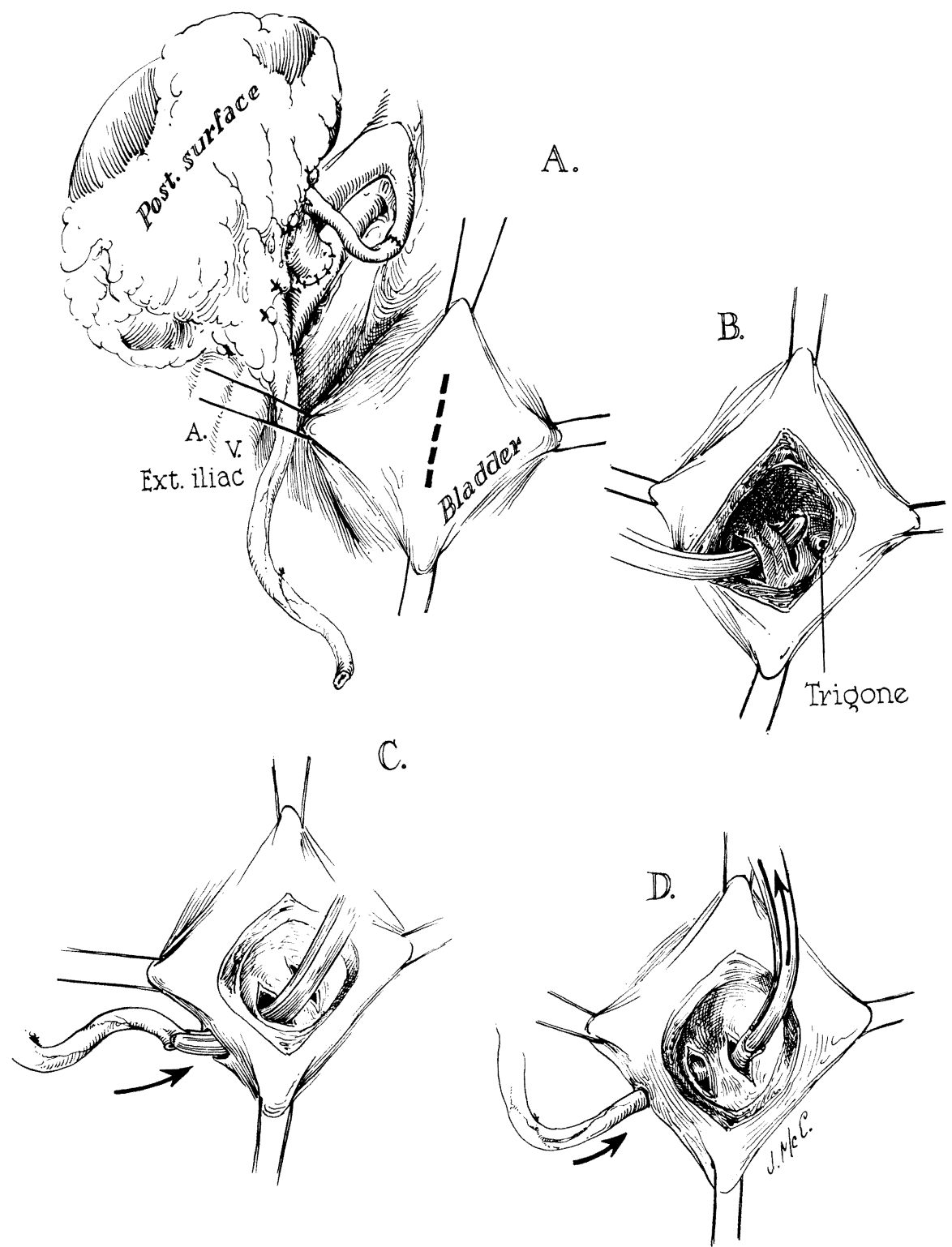

Figure 1 Ureteroneocystostomy. A, The incision in the dome of the bladder is usually no more than $1.5 \mathrm{~cm} . B$, Development of the submucosal tunnel. Often the more lateral counterincision is not necessary. $C$ and $D$, Placement of the ureter within the tunnel. The passage through the muscular layers should be widely dilated. 

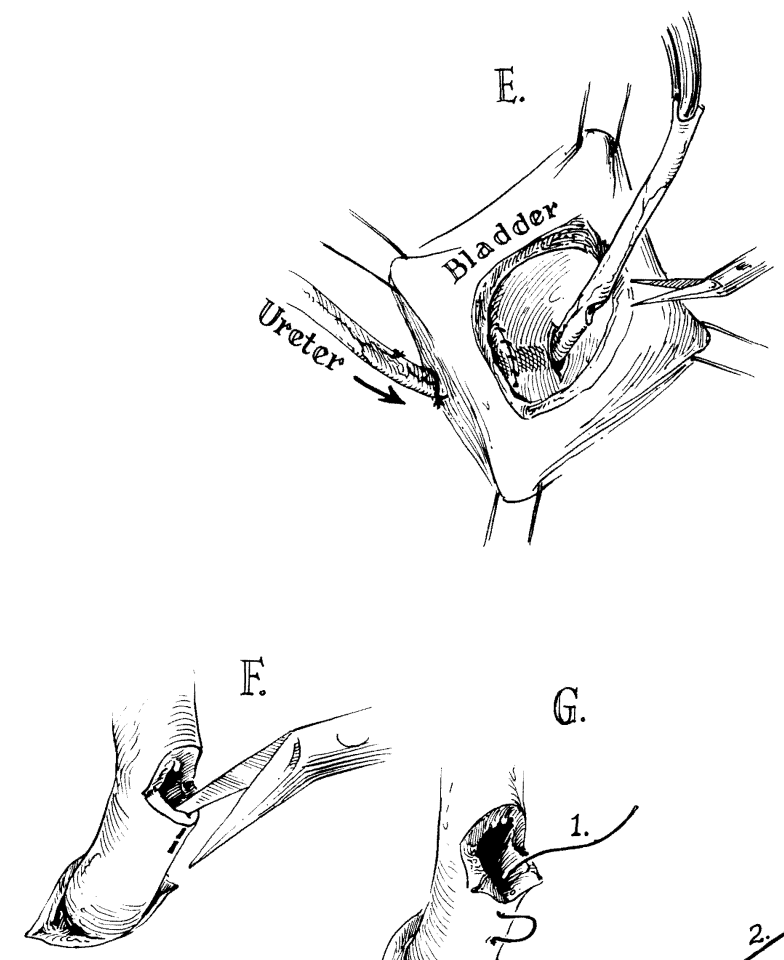

G.
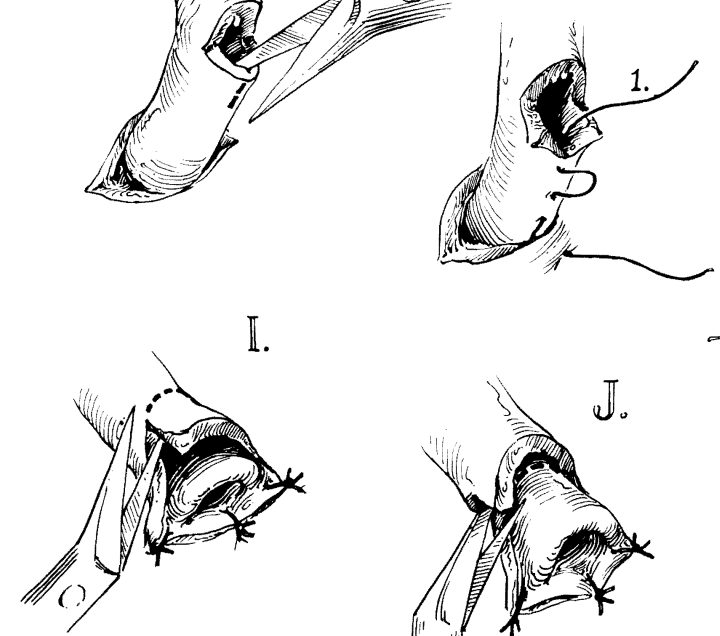

I.
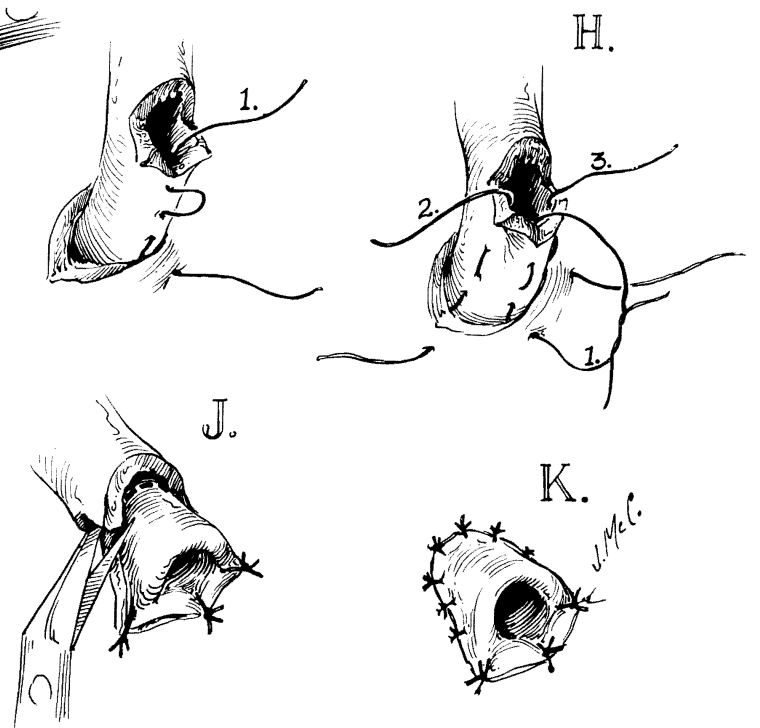

Figure 1 Continued. $E$ and $F$, Trimming of the ureter. $G$ through $J$, Formation of a flat nipple. $K$, Completed ureterovesical anastomosis. The sutures are placed with 5-0 or 6-0 plain catgut on a swaged needle. (From Starzl, T. E., et al.: Urological Complications in 216 Human Recipients of Renal Transplants. Ann. Surg., 172:1, 1970.) 

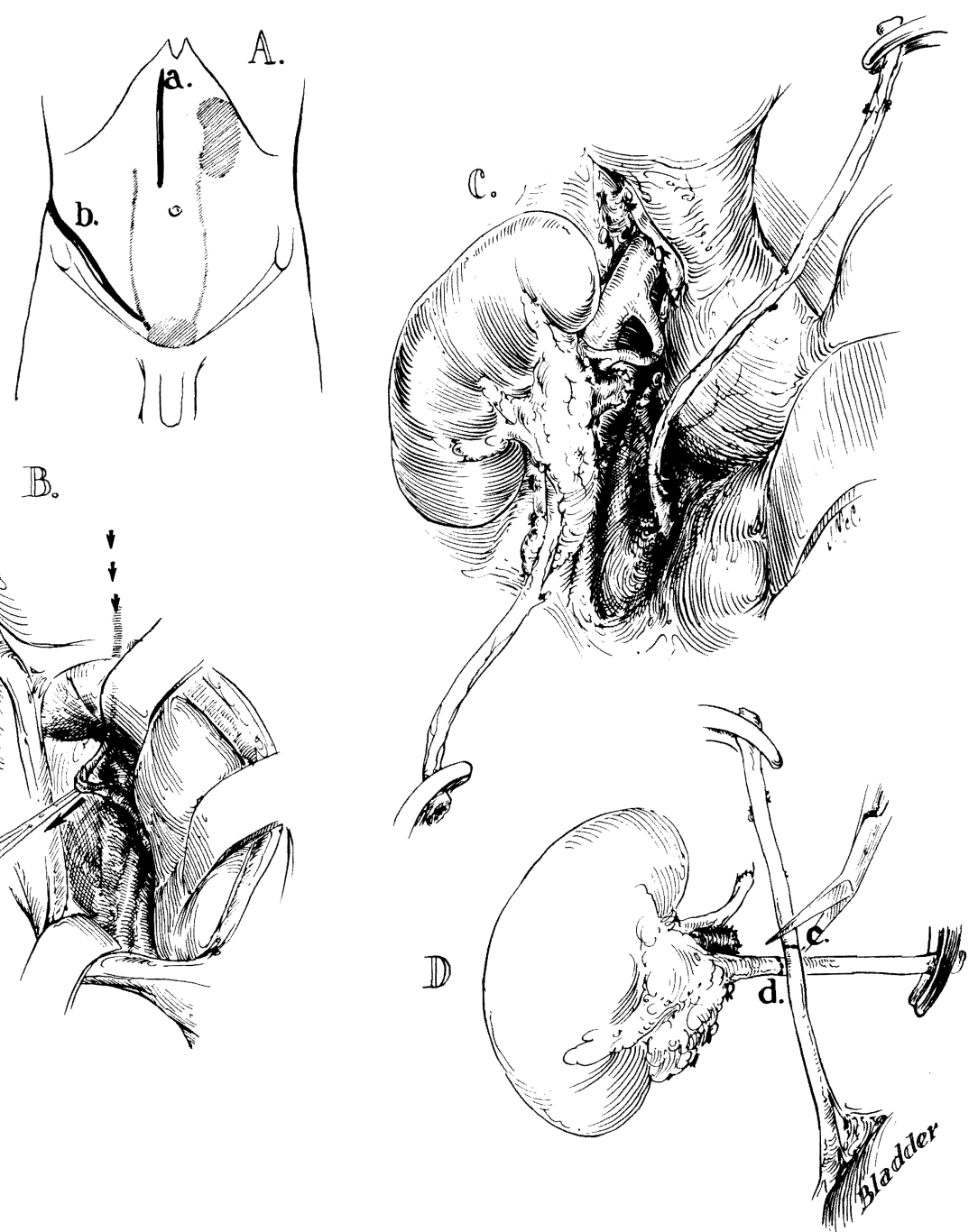

Figure 2 Ureteroureterostomy. A, Incision for bilateral nephrectomy and splenectomy: The ureter is tied just below the ureteropelvic junction (a). The lower incision (b) is for kidney transplantation. B, Recipient site for transplantation, showing the recipient ureter being delivered into the iliac fossa by gentle traction. $C$ and $D$, The vascular anastomoses have been completed. The donor and recipient ureters are positioned to be adjacent to each other and are tailored. 


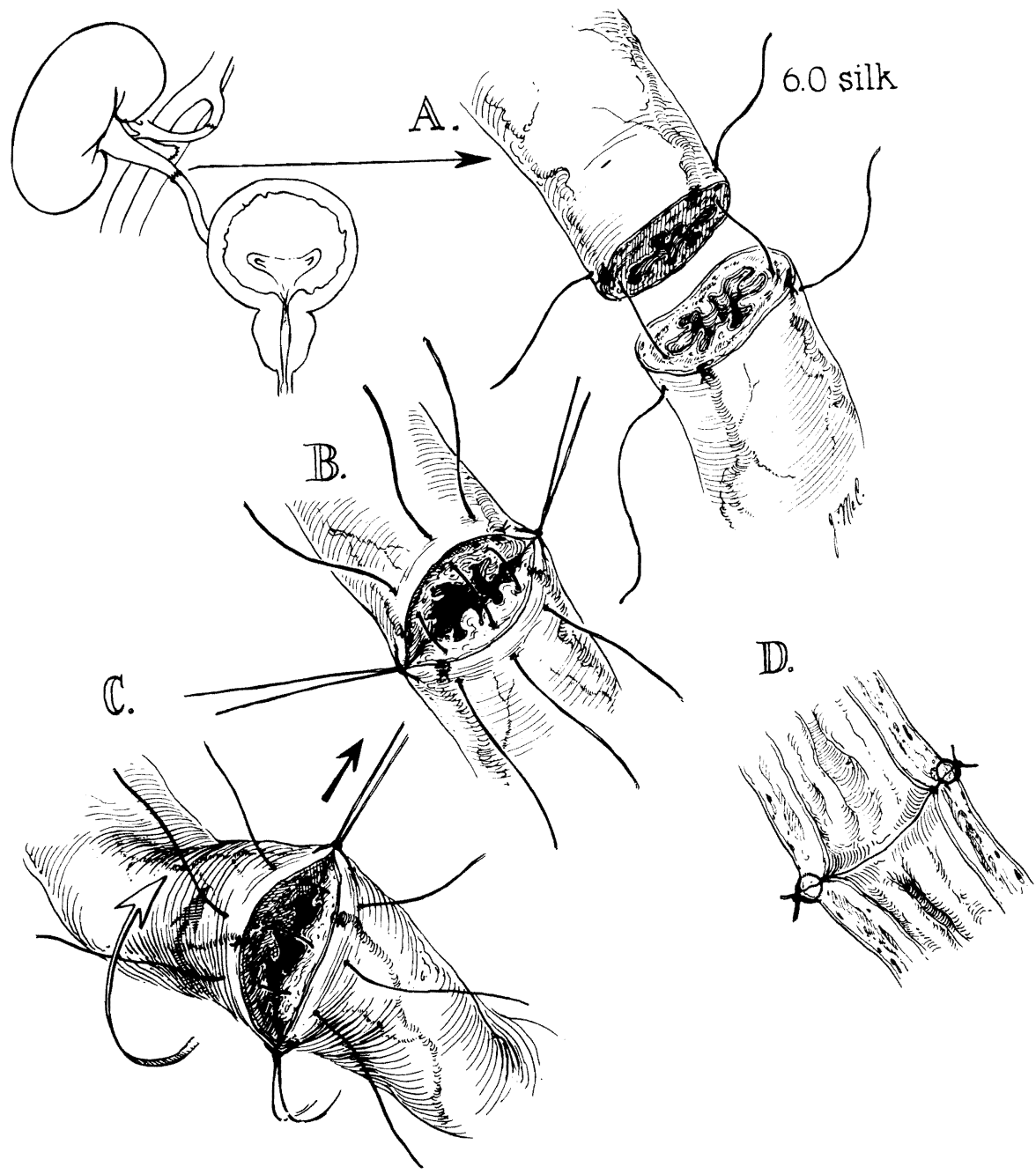

Figure 2 Continued. Single layer anastomosis performed with 6-0 or 7-0 silk swaged on fine cardiovascular needles. In $D$ is shown a longitudinal section with correct placement of the silk sutures. Note the intact mucosa, with no sutures extending into the lumen. (From Starzl, T. E., et al.: Urological Complications in 216 Human Recipients of Renal Transplants. Ann. Surg., 172:1, 1970.) 
bladder, or because of other anatomic considerations such as scarring of the bladder from previous surgery.

With both kinds of ureteral reconstruction, there is approximately a 10 per cent incidence of serious urologic complications. However, the two procedures differ in both the timing of the complication and its character. With ureteroneocystostomy the most frequent complication (3 per cent) was late stricture which usually required reconstruction. Early complications such as urinary fistula were less common and were usually caused by necrosis of either the distal ureter or the renal pelvis. In contrast, with ureteroureterostomy there was a relatively high incidence of early complications; urinary fistula occurred in 6 (10.9 per cent) of the 55 primary ureteroureterostomies. Late stricture was not seen with this kind of reconstruction.

With the development of a urinary tract complication, prompt reoperation is indicated, particularly if the difficulty occurs in the early postoperative period. This urgency for reestablishing a watertight urinary system has no parallel in standard urologic practice. In a patient who has the normal capability to heal and resist infection, most urinary fistulas would be expected to eventually close spontaneously. The same cannot be said for the recipient of a renal homograft, who must be treated with potent immunosuppressive agents that predispose to infection in the transplant wound and retard the healing process that would ordinarily close the fistula. Because of these special considerations, our policy has been to attempt to close urinary fistulas surgically before the supervention of wound sepsis.

Since potentially life-threatening complications have been observed with approximately equal frequency after each kind of reconstruction, a categoric recommendation for one method in preference to the other may not be warranted on statistical grounds. Nevertheless, it is our recommendation that ureteroneocystostomy be the first choice usually, since it requires less technical finesse, is associated with a lower incidence of urinary fistula, and ensures the preservation of long segments of both the donor and recipient ureters for later anastomosis should that become necessary.

In several patients, lymphoceles have been detected by intravenous pyelography by external compression of the patient's bladder or homograft ureter (Fig. 3). In several instances, hydronephrosis had developed with concomitant diminution of renal
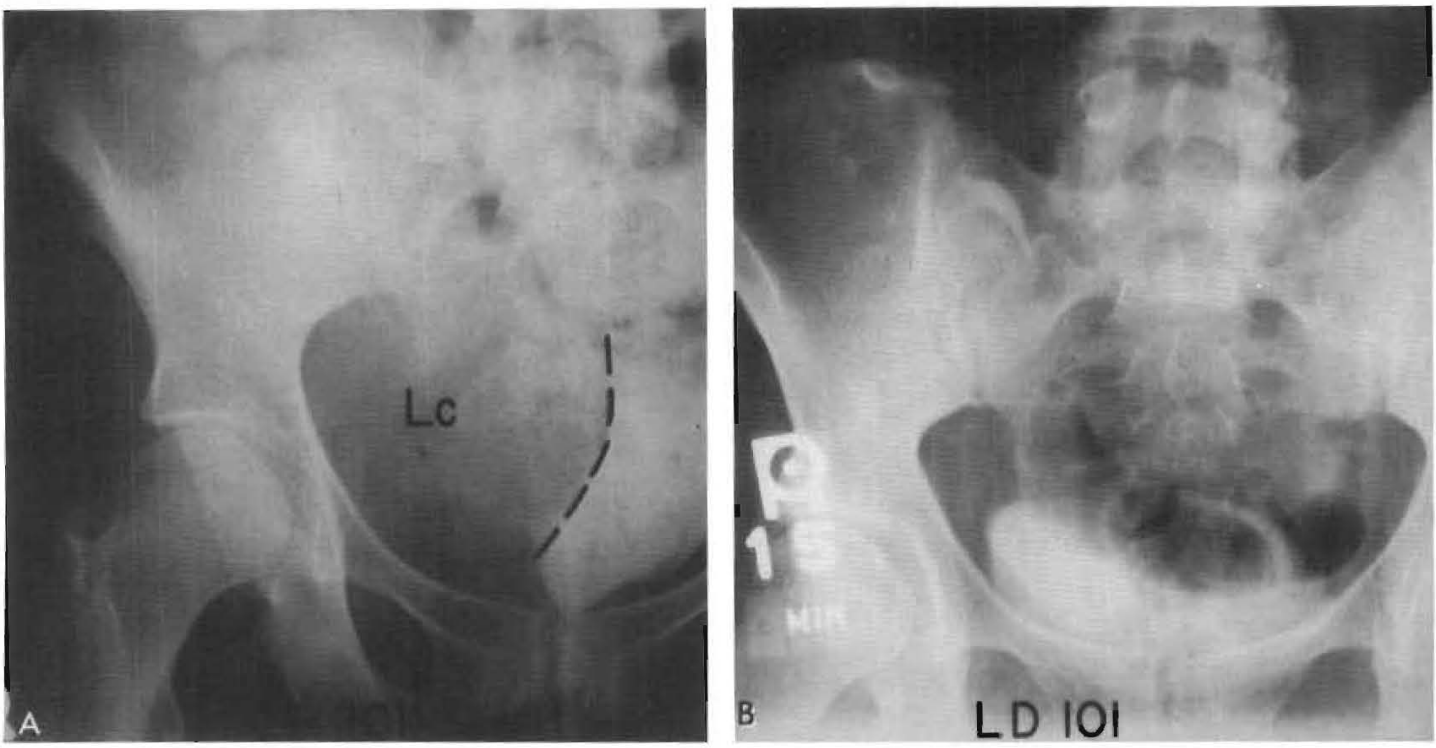

Figure 3 A, Ureteral obstruction 3 months postoperatively, caused by a large lymphocele (Lc) in the transplant wound. The bladder deformity is evident. $B$. After drainage of the lymphocele the hydronephrosis was completely relieved. The patient is alive $3^{1 / 2}$ years after operation. (From Starzl, T. E., et al.: Urological Complications in 216 Human Recipients of Renal Transplants. Ann. Surg., 172:1, 1970.) 
homograft function. Drainage of the lymphocele through the transplant incision resulted in relief of the hydronephrosis and improvement in renal function.

\section{Hepatic Transplantation}

After renal transplantation, the lifethreatening vascular or urinary tract complication may be adverted when necessary by removal of the homograft. With hepatic transplantation, however, this ultimate remedial step cannot be taken, and preservation of the patient's life depends upon successful treatment of the complication without homograft hepatectomy. Thus, it is not surprising that technical misadventures have made a major contribution to both the mortality and the morbidity following liver transplantation. ${ }^{88}$

In the first 25 orthotopic and four auxiliary hepatic transplantations in the Denver series, technical problems were encountered in nearly half the cases. ${ }^{88}$ These included instances of excessive ischemic damage to the homografts by the events of donor death or during organ preservation, of thrombosis or kinking of the blood supply to the transplanted liver, and of biliary duct obstruction.

Vascular Complications. If hepatic arterial occlusion occurs early after transplantation, the complication is uniformly lethal. Death may occur almost immediately from massive hepatic necrosis (Fig. 4). Alternatively, delayed death from regional hepatic infarction with concomitant sepsis may follow this kind of complication.

Venous thrombosis following liver transplantation is rare. In the Denver series there has been one such complication; in this instance, anatomic anomalies of the recipient portal vein and hepatic artery probably played an important role.

Billary Obstruction. Failure to provide adequate biliary tract drainage has been the single most common technical error in hepatic transplantation. ${ }^{13,}{ }^{14,88}$ Our greatest experience has been with cholecystoduodenostomy, but with this kind of reconstruction we have encountered a distressing incidence of biliary obstruction,

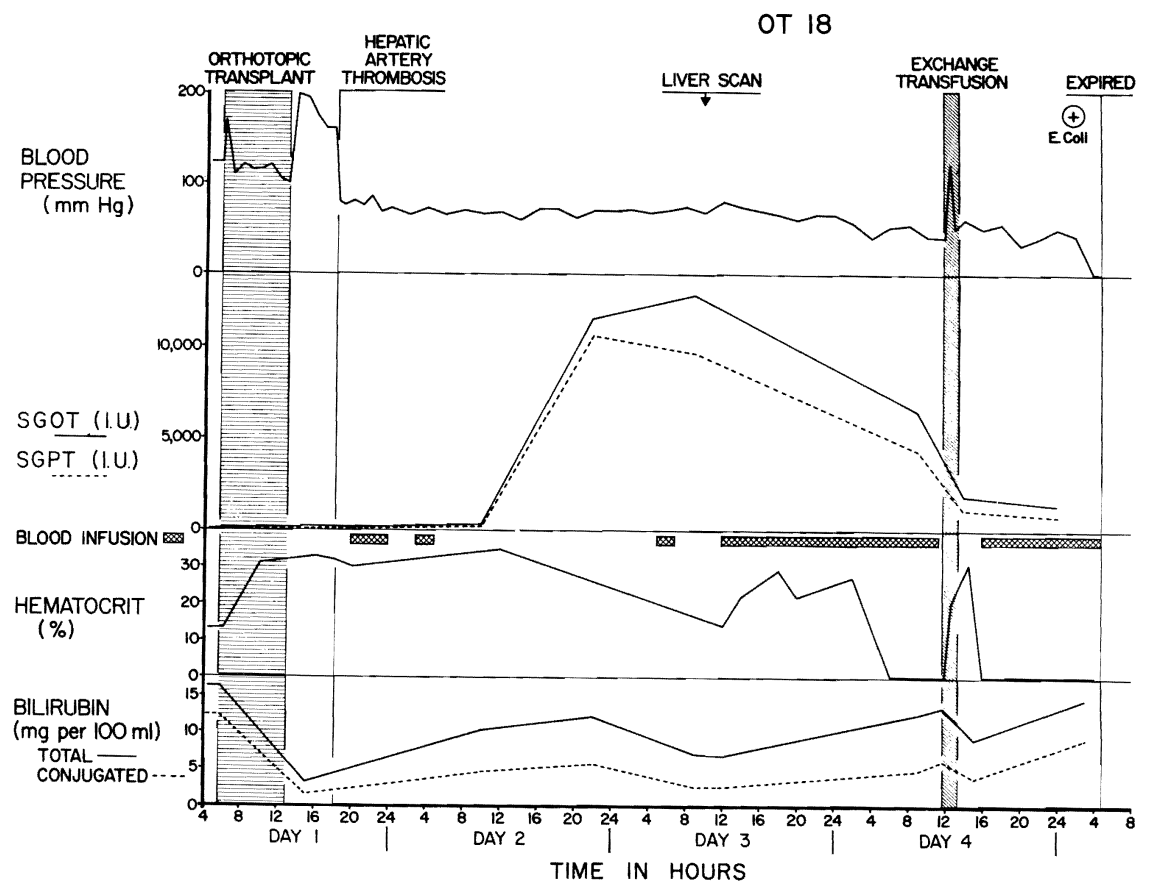

Figure 4 The course of a 1-year-old child with extrahepatic biliary atresia who was treated with orthotopic liver transplantation. The hepatic artery of the homograft apparently underwent thrombosis within a few hours after operation, but this fact was not reflected in transaminase level rises until almost a day later. The eventual drop of the hematocrit to almost zero was due to massive hemolysis. (From Starzl, T. E., Brettschneider, L., Penn, I., Bell, P., Groth, C. G., Blanchard, H., Kashiwagi, N., and Putnam, C. W.: Orthotopic Liver Transplantation in Man. Transplant. Proc., 1:216, 1969. By permission of Grune \& Stratton, Inc.) 
which in almost all instances has been at the level of the cystic duct (Fig. 5). With this complication, there evolves a typical syndrome, including biochemical evidence of biliary obstruction, fever, and other manifestations of sepsis. ${ }^{49}$ Initially, it was assumed that the complication was entirely the result of technical error. An analysis of four such cases by Martineau, ${ }^{49}$ however, has demonstrated the presence of cytomegalovirus (CMV) in cells lining the gallbladder and cystic duct. Swelling and exfoliation of these cells into the lumen may have contributed to the obstruction of the cystic ducts.

At first, the gravity of this situation was not thoroughly appreciated. In some instances. the correct diagnosis was not made until autopsy. When reoperation was carried out in others, it was frequently too late. More recently, the diagnosis has been made earlier and reoperation undertaken. At surgery, the dilated common duct was anastomosed to the hole in the duodenum left by taking down the previous cholecystoduo- denostomy to form a secondary choledochoduodenostomy, with or without stent support. Survival has been achieved in several of these cases.

Following biliary reconstruction with either cholecystoduodenostomy or choledochoduodenostomy, patients may exhibit septic complications not related to obstruction. These have included cholangitis and a syndrome in which the patient is "flooded" with bacteria during rejection crises. In an effort to place the homograft at a distance from the bacteria-laden gastrointestinal tract, several recent patients have been provided biliary drainage with Roux-en-Y cholecystojejunostomy. With this technique, an isoperistaltic limb of jejunum exceeding 18 inches in length is anastomosed to the gallbladder or, alternatively, the common duct. The results thus far are encouraging.

Other Technical Problems. Other Complications directly or indirectly attributable to technical errors at the time of hepatic transplantation include hemorrhage caused by a generalized bleeding cliathesis, ${ }^{26}$
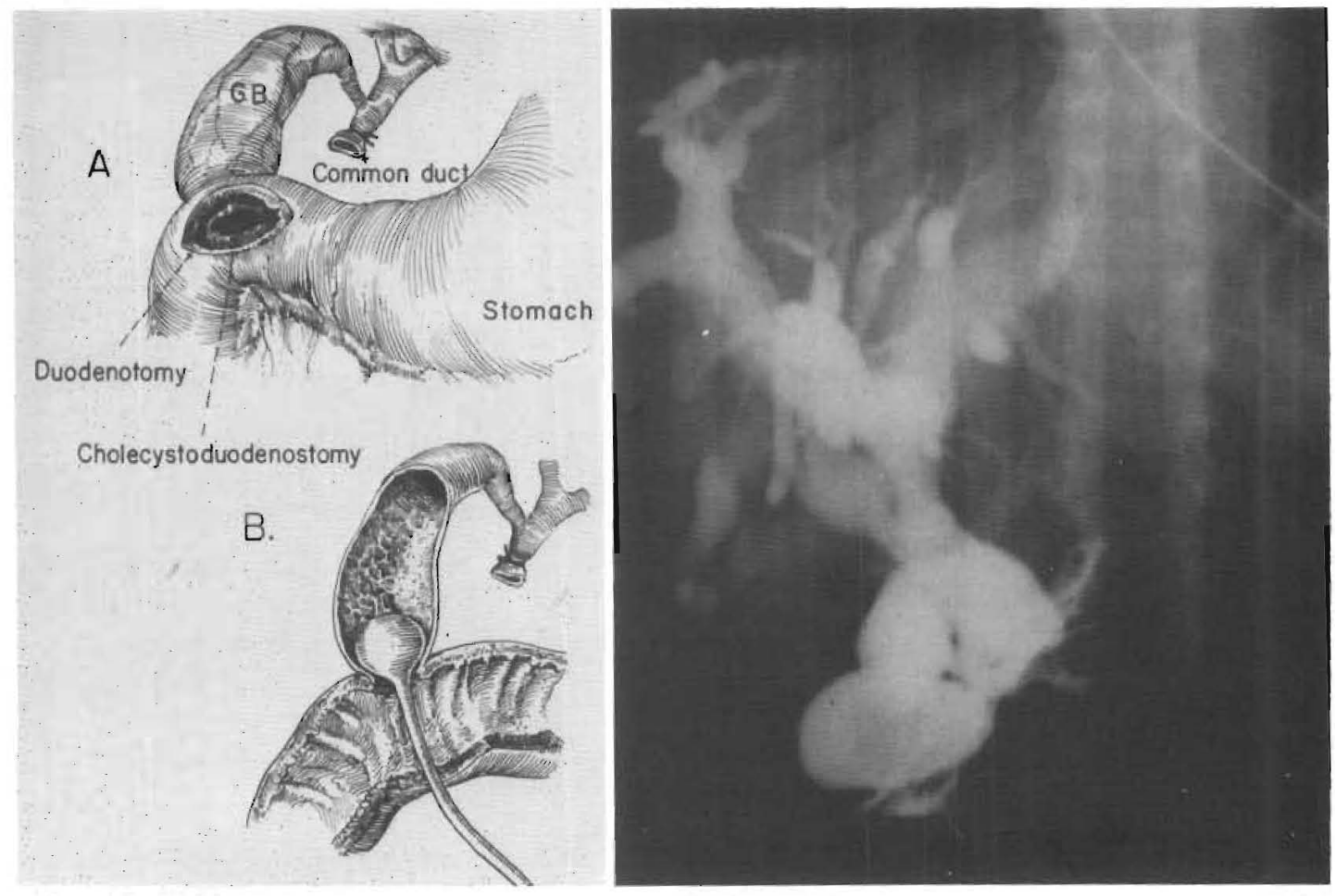

Figure 5 Cholangiography of hepatic homograft. Left, Technique of dye injection through a duodenotomy and the anastomosis. Right, Obstructed duct system in a liver recipient who had primary biliary reconstruction with cholecystoduodenostomy. Subsequent surgery failed to relieve the obstruction and the patient died of sepsis a few weeks later. (From Martineau, G., et al.: Delayed Biliary Duct Obstruction after Orthotopic Liver Transplantation. Surgery, $72: 604,1972$. 


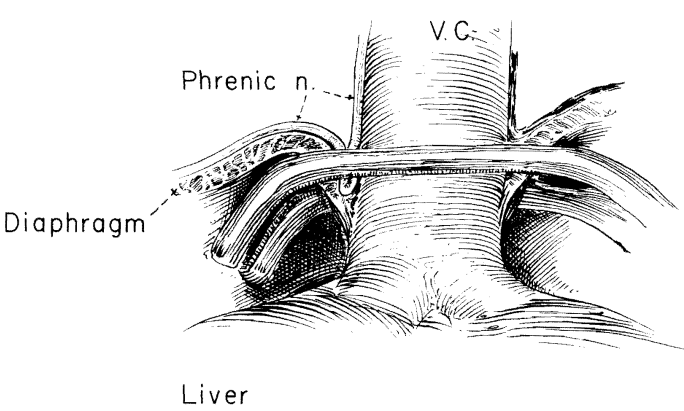

Figure 6 Probable mechanism of operative injury of the right phrenic nerve in four pediatric recipients of orthotopic liver homografts. Note the inclusion of the nerve in the bite of the vascular clamp, which has been placed across the suprahepatic vena cava and which has also included a piece of diaphragm. (From Starzl, T. E.: Experience in Hepatic Transplantation. Philadelphia, W. B. Saunders Company, 1969.)

air embolism following clamping of the vena cava, right diaphragmatic palsy apparently caused by the vascular clamp placed too far superior on the suprahepatic inferior vena cava (Fig. 6), and infarction of the right adrenal gland in the course of recipient hepatectomy. This last complication is an important one for the surgeon to understand, since it may be the cause of uncontrollable hemorrhage. The basis for the complication is the need to sacrifice the right adrenal vein which drains into the excised retrohepatic vena cava (Fig. 7). In about 20 per cent of our cases of orthotopic transplantation, the adrenal gland then has undergone venous infarction and has become the site of hemorrhage that can be controlled only by removal of the gland. In one case, this kind of regional venous hypertension with hemorrhage necessitated reoperation and probably contributed to the death of the patient.

Figure 7 Ligation of the right adrenal vein in the course of recipient hepatectomy. Opening of the bare area of the right hepatic lobe has exposed the adrenal gland. The right adrenal vein, which is usually the only posterior tributary to the retrohepatic vena cava, is then ligated and divided. In about 20 per cent of cases, the adrenal gland will undergo infarction and become the site of hemorrhage which can be controlled only by right adrenalectomy, (From Starzl, T. E.: Experience in Hepatic Transplantation. Philadelphia, W. B. Saunders Company, 1969.)

\section{REJECTION}

The central issue in transplantation of any organ is control of the immunologic process by which tissue that is not genetically identical is normally repudiated. Thus rejection-its diagnosis and its prevention-dominates and influences all other events of the postoperative period.

\section{Hyperacute Rejection}

This is the most convulsive and ruinous immunologic complication that may be visited upon homografts. The explanation for hyperacute rejection has been well worked out in the last 4 or 5 years. ${ }^{42,86,89,92,103,110}$ As far as can be determined, the initiating event is exposure of the transplant to host blood containing preformed antibodies possessing antigraft specificity. Most commonly, these antibodies are of the cytotoxic variety and are the result of presensitization by exposure to histocompatibility or other antigens during blood transfusions, during pregnancy, or in the course of an earlier transplantation. In some patients whose homografts undergo hyperacute rejection, no preformed antibodies can be identified but the assumption that they are present is usually made.

The events of hyperacute rejection occur with great rapidity. After an organ is revascularized it fails to assume a normal pink hue or it initially has this color but loses it

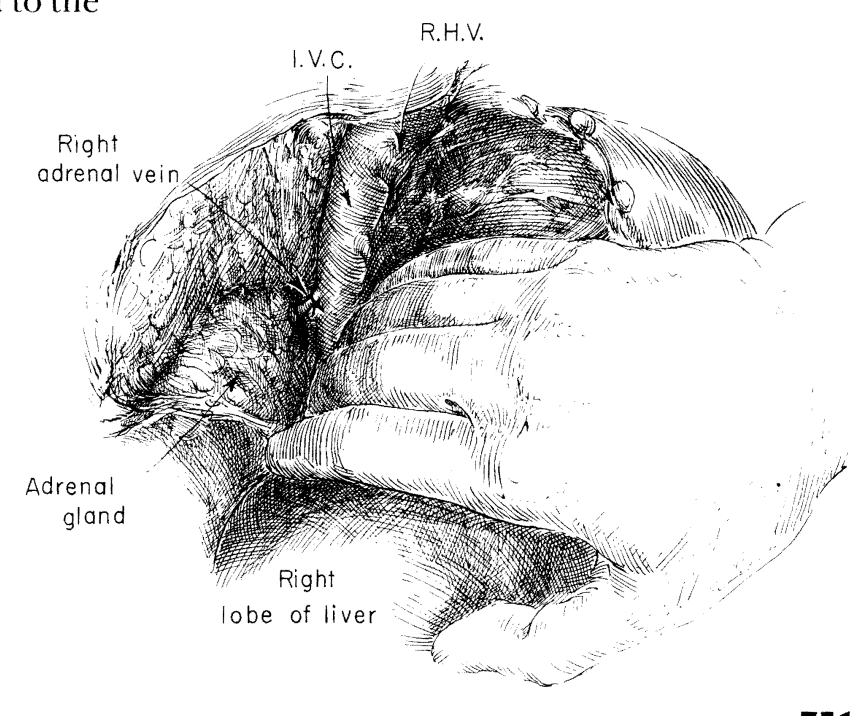


within a few seconds to hours and becomes cyanotic. Not only are antibodies absorbed by the transplant, but essentially simultaneously there is sequestration within the organ of white cells, platelets, and red cells. Finally, there is clearance by the graft of clotting factors. In this way, the blood supply of the graft becomes plugged with complex thrombi, and this leads to its almost instant devascularization.

Once hyperacute rejection has occurred, there are no known remedial steps that can be taken. The best course is to recognize that the homograft has been lost and in the case of the kidney to remove it promptly since it will predictably undergo ischemic necrosis. If a patient undergoes one hyperacute rejection, the chances of this accident occurring again are greatly increased, and special efforts should be made to identify preformed antigraft antibodies before proceeding with a secondary transplantation.

\section{Delayed Rejection}

If homograft rejection occurs despite treatment with immunosuppressive agents, the process usually begins relatively early, within a few days or weeks after operation, when the onset might have been expected had no therapy been given. In Figure 8 are illustrated some of the findings of renal homograft rejection in a patient whose initial treatment was with azathioprine. Typically, there is an initial period of satisfactory homograft function followed by deterioration of this function. In the case shown, the kidney performed perfectly at first, but after about 16 days the BUN began to rise, the creatinine clearance fell, proteinuria increased, there was a tendency to hypertension (controlled by medication), and relative oliguria occurred. At the same time, the patient became febrile and had a leukocytosis. In short, there were the findings of secondary failure of the homograft in a patient who exhibited a systemic febrile illness.

It is now well known that the onset of rejection is no cause for despair since this process is so readily reversible. In the case shown (Fig. 8), the primary treatment with azathioprine was reinforced with heavy doses of prednisone with a resulting prompt reversal of all the adverse findings. Later, it became possible to drastically reduce the doses of prednisone required to prevent a recurrence of rejection, and after 5 months the steroid therapy was stopped altogether. For $9 \frac{1}{2}$ of the 10 years since transplantation, this patient has been treated with smaller doses of the drug azathioprine than those that failed at the beginning of treatment to prevent the onset of a moderately severe rejection crisis.

It would be superfluous to devote more time to a description of the findings of rejection in organs other than the kidney since the changes can be so easily deduced from the natural functions of the organ in question. Suffice it to say that the cardinal features of delayed rejection are those of deterioration of homograft function plus the same systemic manifestations as just described in kidney recipients. As with the kidney, the reversal of the rejection process has been well documented with every organ so far tested. The specific manifestations in all the various organs, including the kidney ${ }^{87}$ liver, ${ }^{88}$ heart, ${ }^{102}$ lung, ${ }^{112}$ and pancreas $^{35,84}$ have been the subject of books, monographs, or articles.

No matter which organ has been transplanted, the magnitude of immunosuppression required to prevent rejection becomes the dominant factor in determining the incidence and severity of the complications whose discussion will constitute much of the remainder of this chapter. If the immunologic barrier encountered is a low one, the amount of prednisone and other drugs required to prevent the onset of rejection will be small and the complications of immunosuppression will be accordingly reduced. In contrast, if major problems are encountered with rejection, high doses of the various agents must be used with predictably adverse effects upon the recipient. In difficult cases, steroid therapy invariably plays a dual role of savior and villain. Since steroids are the only really dose-maneuverable component of any of the immunosuppressive regimens now in common use, rejection is usually dealt with by an increase in the daily quantities of prednisone. The graft can usually be salvaged but with the sometimes devastating side effects that will be described later. 


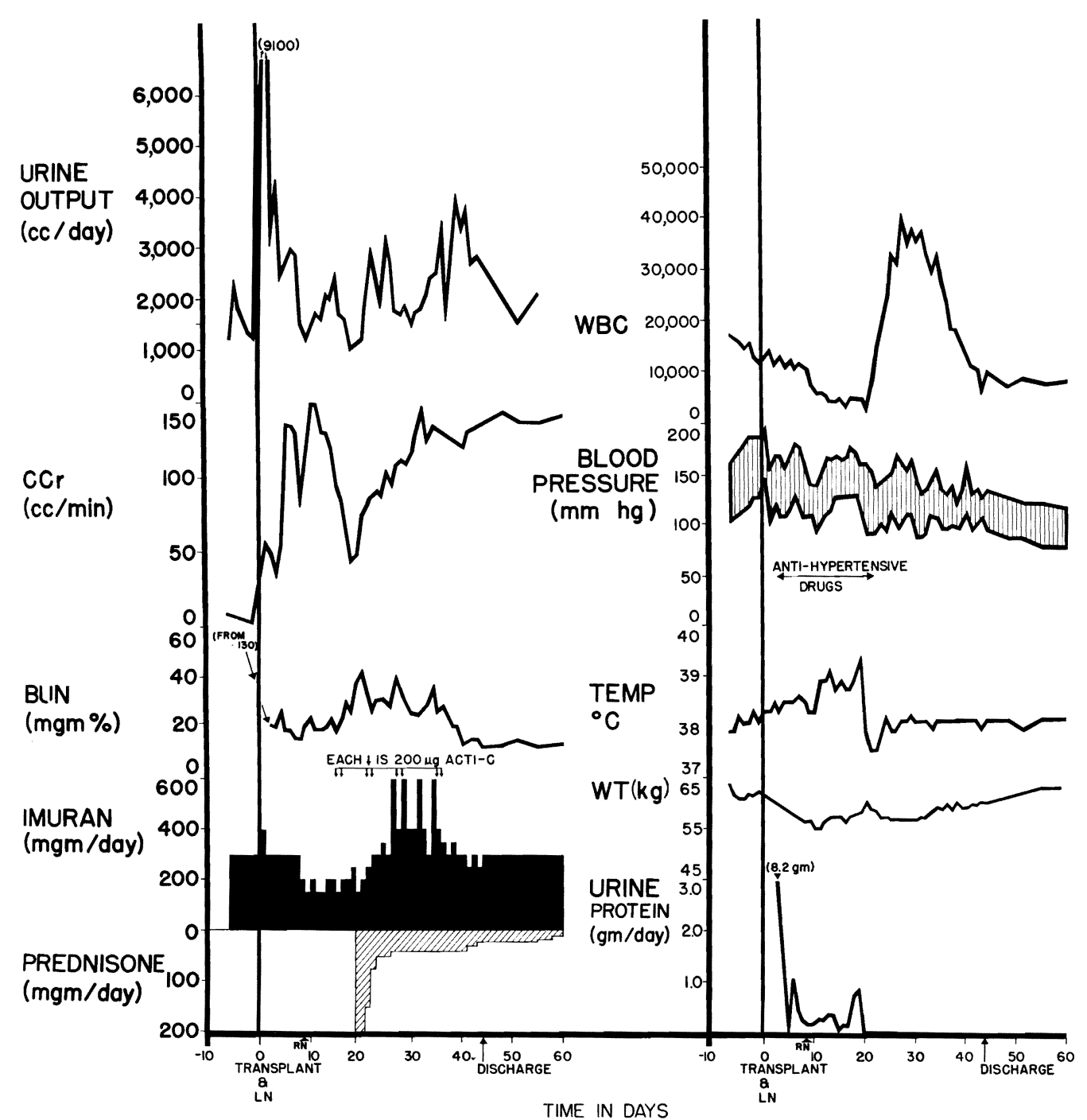

Figure 8 Classic rejection crisis in a patient being treated with the double-drug combination of azathioprine (Imuran) and prednisone. Deterioration of renal function began 17 days after transplantation. All stigmata of rejection are present except for acute hypertension and weight gain, which were successfully prevented by medical treatment. The homograft, transplanted on April 17, 1963, still functions normally 10 years later. Its appearance at biopsy after 2 years was normal. Acti-C, actinomycin C; LN, left nephrectomy at the time of transplantation; RN, right nephrectomy. (From Starzl, T. E., et al. The Reversal of Rejection in Human Renal Homografts with Subsequent Development of Homograft Tolerance. Surg. Gynec. \& Obst., 117:385, 1963. By permission of Surgery, Gynecology \& Obstetrics.)

\section{Chronic Rejection}

The kind of rejection that was just described is thought to be a manifestation of cell-mediated immunity. Many months or years after transplantation, a different kind of insult may come to affect a chronically functioning transplant. With this latter process, there is involvement of the blood supply of the homograft, with intimal and subintimal thickening and eventual occlusion of the arteries to the transplanted organ. ${ }^{25,73,87,88}$ Thus, a transplanted kidney, liver, heart, or other vascularized organ may, in the long run, have its blood supply squeezed off by an attack on the vascular tree (Fig. 9). There has been much speculation that this complication represents an indolent humoral antibody attack upon a transplant by a host that has never completely forgotten its presence.

\section{Renal Transplantation, Rejection, and Hypertension}

Arterial hypertension occurs in almost 100 per cent of renal homograft recipients 

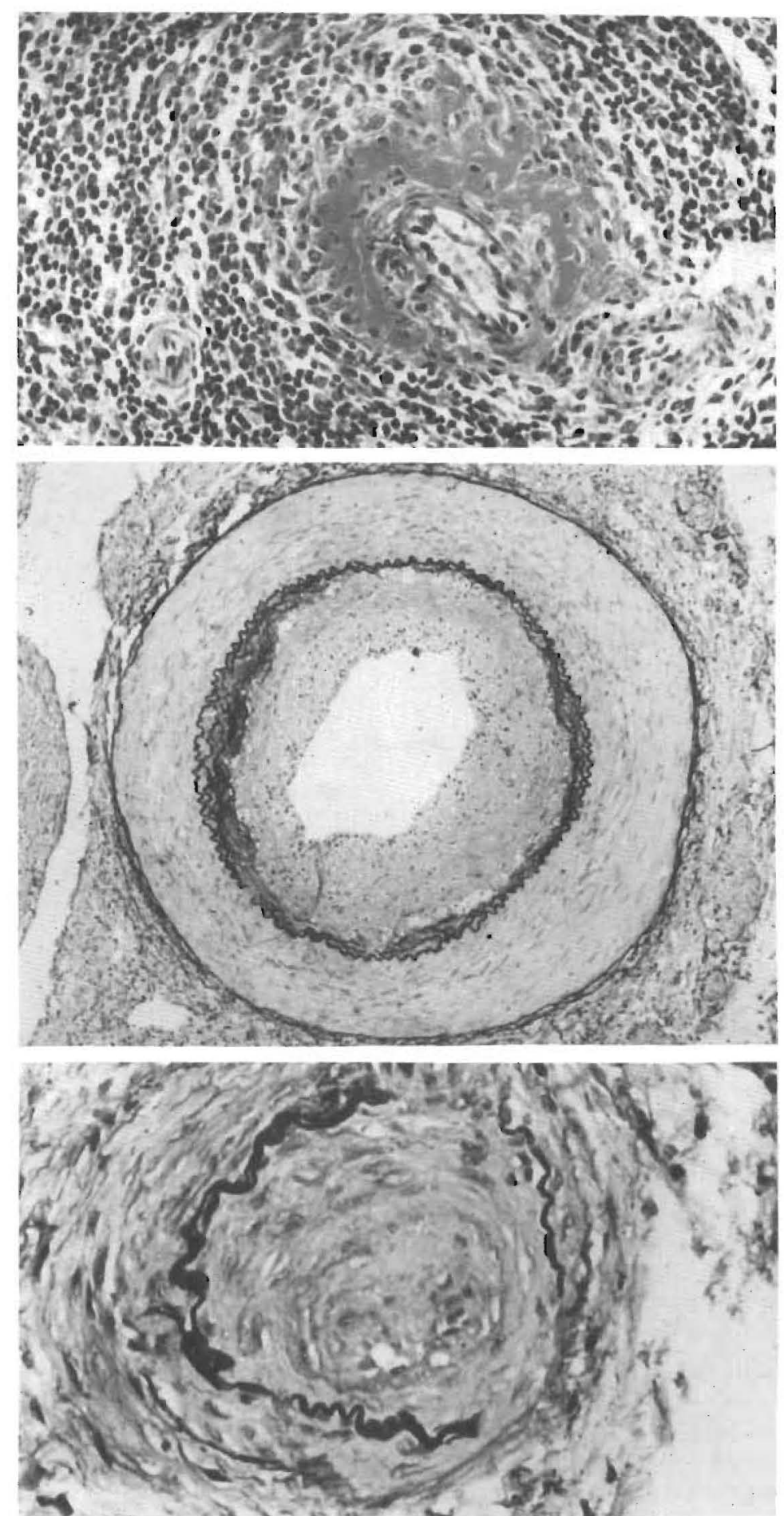

Figure 9 Vascular changes in canine renal homografts. Top, Renal homotransplant at 19 days from a dog treated with azathioprine and actinomycin C. There is fibrinoid necrosis of the whole wall of an interlobular artery, and the surrounding tissues are heavily infiltrated by cells. $\mathrm{H}$ and $\mathrm{E}(\times 180)$. Middle, Renal homotransplant at 739 days from a dog treated with 6-methyl mercaptopurine. An interlobular artery shows diffuse intimal thickening by fibrous tissue. Elastic counterstained with hematoxylin and van Gieson $(\times 30)$. Bottom, Renal homotransplant at 330 days from a dog treated with azathioprine and actinomycin C. An interlobular artery shows marked fibrous intimal thickening which has almost obliterated the lumen of the vessel. The internal elastic lamina has been ruptured. Elastic counterstained with hematoxylin and van Gieson ( $\times 160)$. (From Starzl, T. E.: Experience in Renal Transplantation. Philadelphia, W. B. Saunders Company, 1964.) 
at some time after operation. The greatest incidence is during the first 6 months. With rejection, the factors contributing to a rise in blood pressure include fluid overload due to failure of normal urine excretion, the hypertensive effect of high-dose steroid administration, and the presence of a reninangiotensin response that is apparently caused by the ischemia associated with rejection. Later in the course, this early hypertension very often recedes in successful cases but with chronic rejection it may return. The hypertension in renal homograft recipients has been thoroughly discussed in the literature. ${ }^{9,24,87,107}$

\section{Recurrent Glomerulonephritis}

It may be that the glomerulonephritis commonly seen in renal homografts months or years after transplantation is also a manifestation of a humoral antibody phase of rejection. ${ }^{5,52,98}$ Two kinds of glomerulonephritis have been seen in transplanted kidneys. In one variety, anti-glomerular basement membrane (anti-GMB) antibody has been found by immunofluorescence techniques, giving the typical appearance of the single glomerulus depicted in Figure 10. This glomerulonephritis is the human analogue of the experimental pathologic process known as Masugi nephritis in which the antibody directly attacks glomerular basement membrane. ${ }^{18}$

The other kind of glomerulonephritis observed in transplanted kidneys is comparable to experimental serum sickness nephritis in which antigen-antibody complexes are formed outside the kidney but eventually trapped there because of the peculiarly effective filtration of the renal microcircula-
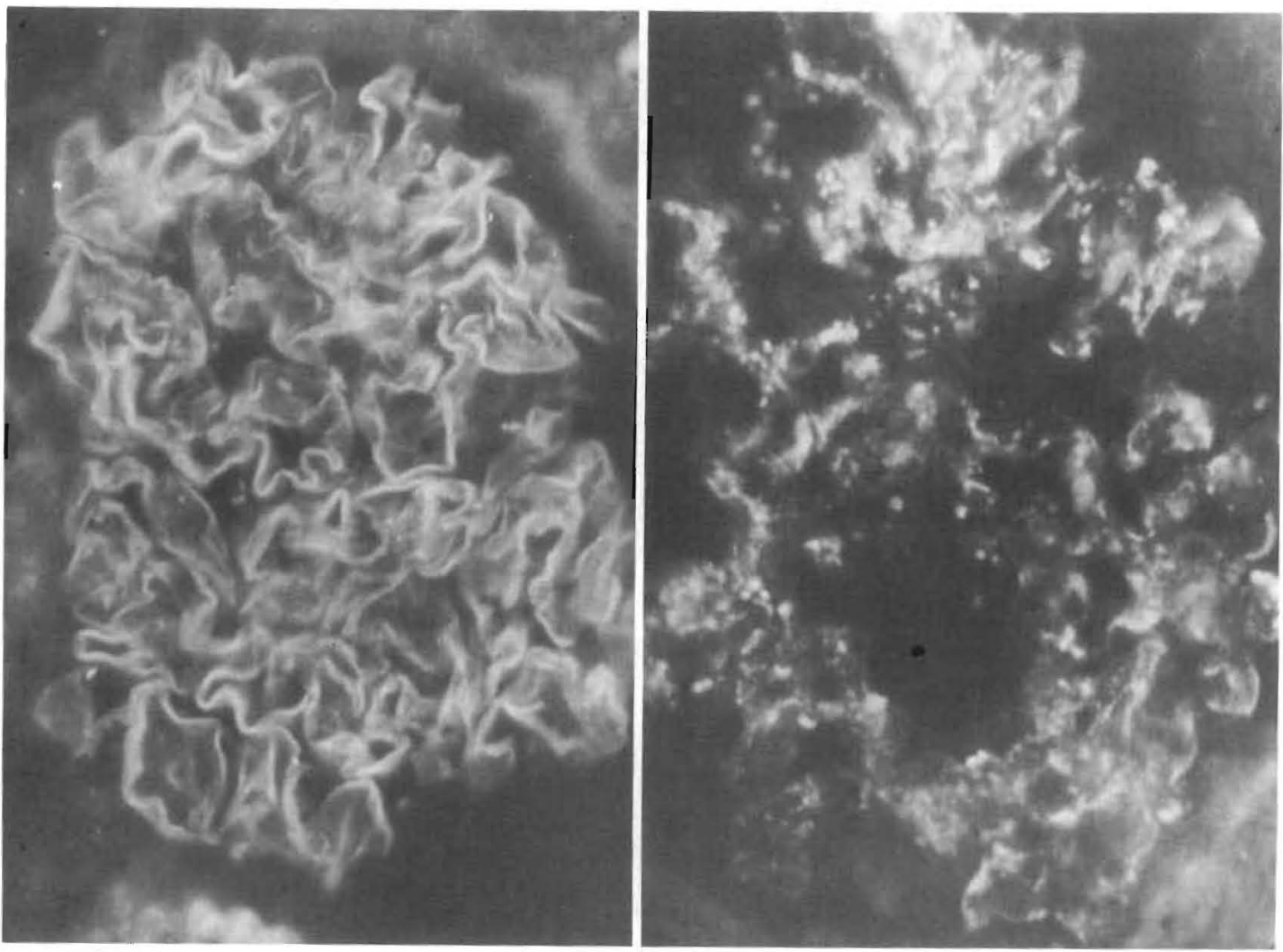

Figure 10 Immunofluorescent photomicrographs of typical glomerular lesions in renal homograft biopsies. Left, Typical linear fixation of lgG on glomerular walls of a biopsy specimen obtained 23 months post transplanlation. The patient had normal renal function at the time of biopsy. Right, Typical discontinuous granular deposits of $\lg 30$ months post transplantation. 



Figure 11 An example of glomerulonephritis which evolved rapidly in a cadaveric renal homograft. A, Biopsy at 24 hours. There is interstitial edema, tubular damage, and hyaline thickening of the wall of an arteriole (arrow). B, The same kidney at autopsy 6 days after transplantation. Homograft had remained oliguric during that period. There is patchy fibrinoid necrosis of the glomerular tuft capillaries and early crescent formation in Bowman's capsule. The tubules are severely damaged and the distal parts contain red cells. C, One of the recipient's own kidneys. The glomerular tuft shows some fibrinoid necrosis and a large partly fibrosed crescent. These changes were part of a rapidly progressive glomerulonephritis but similar lesions may develop slowly over months or years in renal homografts. $\mathrm{H}$ and $\mathrm{E}(\times 175)$. (From Starzl, T. E.: Experience in Renal Transplantation. Philadelphia, W. B. Saunders Company, 1964.) 
tion. When such complexes are trapped within the kidney, their immunofluorescent appearance is like that shown in Figure 10. The kidney slowly undergoes damage over the ensuing months or years by the attraction of host inflammatory responses including the deposition of immunoglobulin and complement. ${ }^{18}$ By light microscopy, the histopathologic manifestations of these events or those with anti-GBM nephritis may be proliferative, lobular, or other kinds of glomerulonephritis that have distinction by their morphologic characteristics (Fig. 11).

The development of glomerulonephritis in transplanted kidneys has been well documented by reports from a number of institutions. ${ }^{27}, 28,44,53,54,58,71,98$ At one time, the major emphasis was placed on the "recurrence" of the original disease. It is true that the chance of glomerulonephritis developing in a renal homograft is greater if this was the orginal diagnosis, and in a number of such cases the appearance of the recurrent disease has been precisely the same as that of the original disease in the native kidneys. However, it has also been well documented that glomerulonephritis may occur in kidneys transplanted to recipients whose original kidneys had been destroyed by other than autoimmune processes. ${ }^{98}$ Thus, glomerulonephritis has been seen in renal homografts transplanted to patients with polycystic disease, cystinosis, and pyelonephritis, to mention only three examples.

Once glomerulonephritis has developed in a renal homograft, there is no specific therapy. These kidneys almost always leak protein, and the proteinuria may become so extreme as to necessitate transplant nephrectomy. More commonly, the proteinuria is only one manifestation of deteriorating function in a course that leads to retransplantation or a return to dialysis. In a few of our patients with otherwise good renal function, stable severe proteinuria with albumin losses of 5 to $10 \mathrm{gm}$. per day has developed. When efforts have been made late after transplantation to reverse proteinuria with increased doses of steroids, the results have usually been disappointing in that the objective of reversing the late changes is not realized and at the same time the penalties of increased immunosuppression must be paid. Thus, in most cases, we accept the residual function these homo- grafts can provide and then remove them when the clinical result is no longer acceptable.

\section{IMMUNOSUPPRESSION AND ITS CONSEQUENCES}

As already stated, the condition that makes organ transplantation different from other surgical undertakings and that endows it with special hazards is immunosuppression. In essence, it is necessary to systematically weaken the immune system of the recipient so that a vigorous reaction against the alien tissue does not occur. The means by which this objective is achieved are variable.

\section{The Different Therapeutic Regimens}

The "modern" era of whole-organ transplantation was ushered in in 1962 by the use together of the two agents azathioprine and prednisone, as described earlier (see Fig. 8). In our center, and in virtually every other one that was active in that era, these two agents provided the essence of treatment. ${ }^{34}$, 55, 95, 111 As already noted, the heaviest immunosuppression was required early after transplantation, but subsequently it often became possible to reduce the dosage required to maintain chronic function of the homograft. If minimal doses sufficed to prevent rejection long after operation, the prognosis of the patient proved to be good, whereas if protracted heavy immunosuppression, particularly with steroids, was required, the outlook was far less favorable. The use of azathioprine and prednisone together has often been referred to as "double-drug" therapy.

In 1966, heterologous antilymphocyte globulin (ALG) was introduced at the University of Colorado as an addition to azathioprine and prednisone in a multiple-agent regimen that has been known as a "tripledrug" program. ${ }^{93}$ With this triple-drug regimen, ALG is used for the first few weeks or months after transplantation, during that time when the need for aggressive immunosuppression is the greatest. After its discontinuance, long-term therapy with azathioprine and prednisone is continued (Fig. 12).

In early 1971 at our institution, a system- 


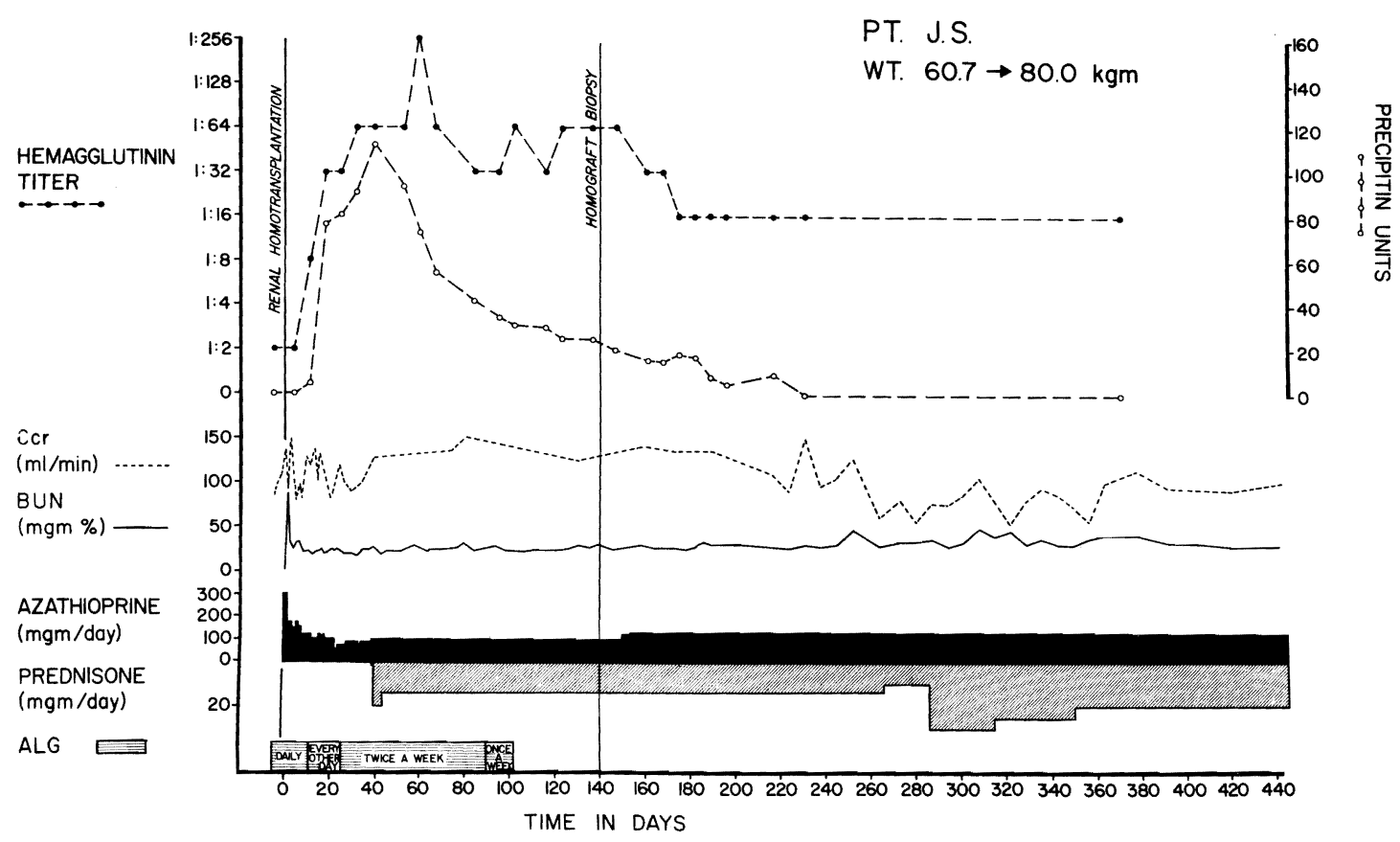

Figure 12 The course of a patient who received antilymphocyte globulin (ALG) before and for the first 4 months after renal homotransplantation. The donor was an older brother. There was no early rejection. Prednisone therapy was started 40 days postoperatively because of the high rises in the serologic titers which indicated a host response against the injected foreign protein and which warned against a possible anaphylactic reaction. Note the insidious onset of late rejection after cessation of globulin therapy. This was treated by increasing the maintenance dose of steroids. (From Starzl, T. E., et al.: Heterologous Antilymphocyte Globulin, Histoincompatibility, Matching, and Human Renal Homotransplantation. Surg., Gynec. \& Obst., 126:1023, 1968. By permission of Surgery, Gynecology \& Obstetrics.)

atic trial was begun to evaluate cyclophosphamide, an alkylating agent, as a substitute for azathioprine. ${ }^{100,101}$ In all new cases of renal as well as hepatic transplantation, initial therapy with cyclophosphamide, prednisone, and heterologous ALG was given. It is interesting that cyclophosphamide as the

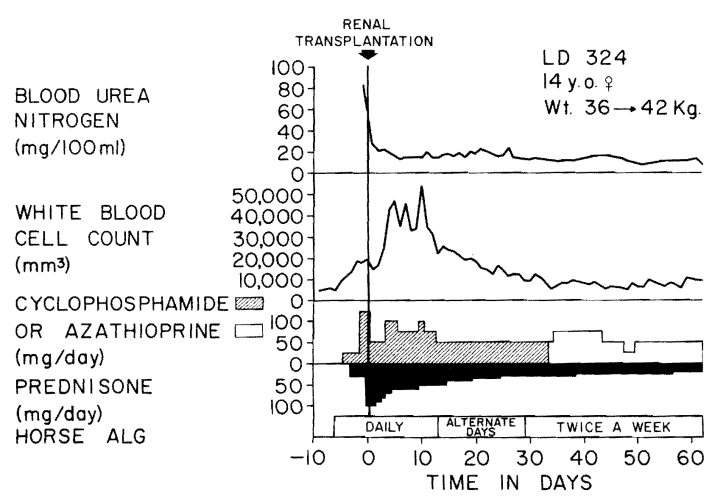

Figure 13 Typical triple-drug immunosuppressive therapy with cyclophosphamide (Cytoxan) after renal transplantation. Cyclophosphamide was begun the day before transplantation and continued postoperatively until there was a tendency toward leukopenia. At that time, therapy with cyclophosphamide was interrupted, and azathioprine was begun. Chronic immunosuppressive therapy has been continued with azathioprine. primary cytotoxic agent has produced approximately the same results as azathioprine. Later on in the postoperative course, after some weeks or months, azathioprine is usually substituted for cyclophosphamide mainly because there is far more information about the long-term use of azathioprine in human beings than is available for cyclophosphamide. Thus, the typical therapy for patients treated at the University of Colorado at the present time is shown in Figure 13.

In addition to these major treatment programs, a number of adjuvant measures have been described although none are sufficiently potent to prevent the onset of early homograft rejection. These measures include splenectomy, ${ }^{87}$ thymectomy, ${ }^{97}$ local homograft irradiation, ${ }^{33}$ intravenous actinomycin $\mathrm{C}$, and thoracic duct drainage. ${ }^{21,22,56}$

\section{Problems of Intrinsic Toxicity}

The side reactions of immunosuppressive agents may be mediated by a straightforward mechanism of drug toxicity. 
Azathioprine. In dogs, this agent has easily demonstrable hepatotoxicity. Doses comparable to those used in humans produce increases in SGOT and SGPT in essentially every animal (Fig. 14). The animals depicted in Figure 14 also lost weight and became anemic. Although jaundice was not noted in these 18 dogs, icterus has also been observed in this kind of canine experiment.

An extreme degree of hepatotoxicity of azathioprine is apparently a relatively species-specific finding in the dog. Fortunately, it is not a consistent problem in the human being. Even so, we believe that liver injury from this agent has been seen in patients, as will be demonstrated later.

It goes without saying that the most striking and specific toxic effect of azathioprine is bone marrow depression if the drug is given in excessively large doses.

Prednisone. The other immunosuppressive agent that has extremely important direct toxic effects, particularly on the gastrointestinal tract, is prednisone. The adrenal corticosteroids, when administered over long periods of time, can (1) cause fatty infiltration or even cirrhosis of the liver, (2) induce pancreatitis and diabetes mellitus, and

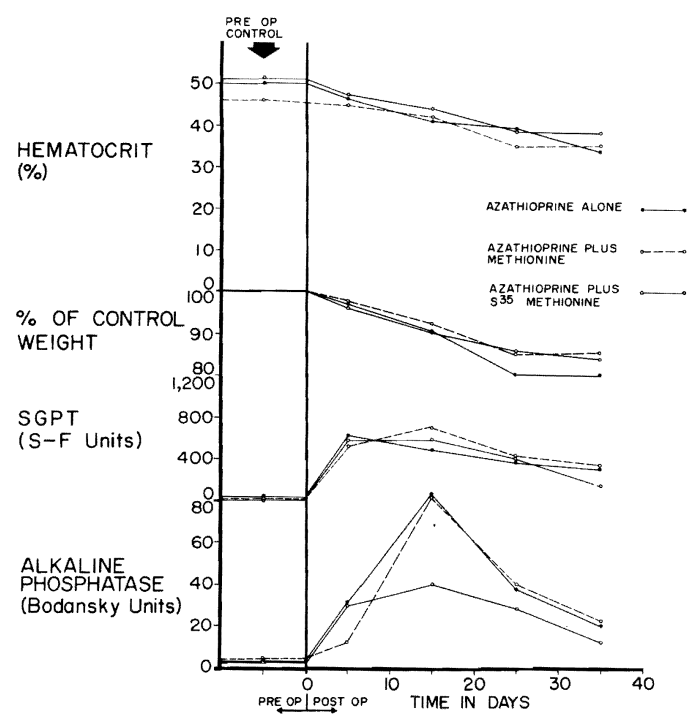

Figure 14 The toxicity of azathioprine when used alone or in combination with ${ }^{35} \mathrm{~S}$-methionine. Six dogs were in each of the three test groups. There were easily detectable abnormalities of liver function but jaundice did not develop. The azathioprine doses were 1 to $4 \mathrm{mg}$. per kilogram per day. Note that the animals tended to lose weight and become anemic. (From Starzl, T. E., et al.: Factors Determining Short- and Long-Term Survival after Orthotopic Liver Homotransplantation in the Dog. Surgery, 58:131, 1965.)
(3) cause ulceration of the duodenum and other parts of the bowel with gastrointestinal hemorrhage or perforation, to mention only a few of their effects.

Among younger patients, the life-threatening complications of prednisone may be of less immediacy than the cosmetic effects. To a sensitive teenager, the most dreaded changes may be the development of severe acne, other unacceptable facial disfigurations, a buffalo hump, and striae of the abdominal wall or elsewhere. More will be said later about the role of prednisone in causing skeletal changes.

Cyclophosphamide. As is the case with azathioprine, cyclophosphamide administration must be monitored scrupulously because of its ability to cause profound bone marrow depression. In addition, cyclophosphamide may have important effects upon the gastrointestinal tract. When used alone in large doses, it has caused diffuse or discrete gastrointestinal ulceration or massive hepatic necrosis. ${ }^{6}$ Hemorrhagic cystitis has come to be recognized as a classic complication of administration of the same doses. ${ }^{78}$

Until recently, cyclophosphamide has been used for its immunosuppressive qualities most extensively by those interested in bone marrow transplantation. ${ }^{79}$ The agent was given for a few days at doses as high as $100 \mathrm{mg}$. per kilogram per day in an effort to induce tolerance. In whole-organ recipients, cyclophosphamide has been used quite differently, usually in doses that are little greater than $1 \mathrm{mg}$. per kilogram per day, but on a chronic basis. Under these circumstances, cyclophosphamide has seemed neither more nor less dangerous than azathioprine. ${ }^{100,101}$

Heterologous ALG. Some of the most important side effects with ALG afflict the kidney. Renal damage may result if the ALG contains specific anti-GBM antibody which attaches to and injures the glomerular basement membrane. More commonly, antibodies may be generated extrarenally in response to the injected antigen. Then, circulating soluble antigen-antibody complexes are formed which may lodge in the kidney and cause a lesion analogous to serum sickness nephritis. Fortunately, these kinds of nephritis have been seen very rarely. ${ }^{43,}, 99,106$

The most dreaded complication of heterologous ALG is the development of anaphylactic reactions, which have been ana- 
lyzed by Kashiwagi. ${ }^{40}$ In our center, these reactions have caused the death of two patients in the course of the last 6 years. An anaphylactic reaction is thought to result from an antigen-antibody union that secondarily triggers the release of humoral substances (from mast cells and other cells) which in turn may pass to widely distributed targets, especially those containing smooth muscle. The humoral agents that have been implicated in anaphylaxis of experimental animals or man have included histamine, slow-reacting substance (SRS), bradykinin, and serotonin. ${ }^{59}$ Since the initiating event in an anaphylactic reaction is an antigen-antibody reaction, it goes without saying that the risk of this complication increases with repetitive exposure to foreign protein, and so the patient receiving ALG chronically should be watched carefully for any suspicious signs.

When an anaphylactic reaction occurs, in retrospect there have usually been plenty of warning signs. A feeling of chest constriction has been a common, seemingly minor complaint. If this is ignored, a later reaction may lead to profound cyanosis. Arterial blood gases were determined in some of our patients and the $\mathrm{PO}_{2}$ was recorded as low as $20 \mathrm{~mm}$. Hg. In the fatal cases, massive pulmonary edema ensued which was uncontrollable by any means.

In some instances a foreboding of impending death may be complained of. In fact the two patients who died in our center from anaphylactic reactions both bitterly resisted the last injections of ALG they were given on the grounds of a premonition of death.

Once an anaphylactic reaction has occurred, it must be treated with great decisiveness and vigor. Usually the intravenous injection of $1 \mathrm{gm}$. of hydrocortisone (SoluCortef) will interdict the potentially lethal manifestations. It may also be desirable to give intravenous diphenhydramine (Benadryl) and eventually even intravenous or intracardiac epinephrine may become necessary.

If the ALG has any significant amount of antiplatelet activity it is entirely possible for it to cause profound thrombocytopenia despite the presence of good bone marrow function.

\section{Immunologic Invalidism}

The kind of direct pharmacologic toxicity just described must be borne in mind by anyone treating patients chronically with any of the drugs used in the several immunosuppressive regimens that have now been widely accepted. However, far greater in importance than this kind of direct toxicity is the immunologic invalidism that is deliberately produced, and efficiently so, by the agents in question. From this weakening of the immune system derive the most serious and dreaded complications seen in the population of transplant recipients. To the extent that the immune system must be suppressed in order to retain function of the graft, the recipient loses the capacity to react forcibly to other inimical environmental antigens, including those of bacteria.

Thus, an increased susceptibility to infection is the price for survival. If an invading microorganism causing an infection is a common bacterium against which effective antibiotics are available, the resulting problem can usually be dealt with. But if the invading microorganism is an opportunistic one of normally low pathogenicity and for which no effective antibiotic therapy is available, the outcome is commonly tragic.

What has just been described is a loss of the surveillance of the host to bacteria. It has become recognized that the loss of immunologic surveillance may have more wide-reaching effects including an increased incidence of de novo malignancies, as will be documented, along with a further account of the infectious complications, in the subsequent sections.

\section{COMPLICATIONS AFFECTING THE ESOPHAGUS, STOMACH, AND DUODENUM}

Esophagus. The most frequent disorder of the esophagus post transplantation has been esophagitis. Invariably, this is associated with stomatitis. If a recipient complains of substernal pain while eating and if ulcerations of the oral mucosa or lips are found, a presumptive diagnosis can be made. The painful lesions of the mouth and lips have been shown to be caused by the 
herpes simplex virus, but this infection is frequently associated with Candida albicans infestation. Treatment with nystatin (Mycostatin) oral suspension and tablets is instituted to control the Candida infection, but if this does not control the moniliasis, a course of systemic therapy with amphotericin B may be required.

The dangers of monilial esophagitis, particularly when the esophageal mucosa has already been damaged by herpetic ulceration, are perforation and dissemination. A month after transplantation one of our patients incurred cliffuse ulcerations and sloughing of the esophagus (Fig. 15), as well as of most of the rest of the gastrointestinal tract (Fig. 15), leading to death from esophageal perforation within a few days. Several other patients have died of dissemi- nated Candida albicans infection with multiple abscesses in several organs.

Stomach and Duodfnum. In caring for patients treated with renal homotransplantation, the need often arises to treat surgically a variety of nonurologic intra-abdominal complications. The single most common cause of difficulty has been gastric or duodenal ulceration with perforation or hemorrhage. Some of these complications developed during pretransplantation dialysis. Under these circumstances, vagotomy plus pyloroplasty or gastric resection should be performed before transplantation is done, since after the institution of immunosuppressive therapy the steroid component of treatment may make medical management even more difficult.

In a book published in 1964 based upon
Figure 15 An example of monilial esophagitis with diffuse ulcerations and sloughing of mucosa. Top, The esophagus and stomach at autopsy. The remainder of the gastrointestinal tract showed similar areas of involvement. Bottom, The tracheobronchial mucosa was also the site of ulcerations and sloughing.
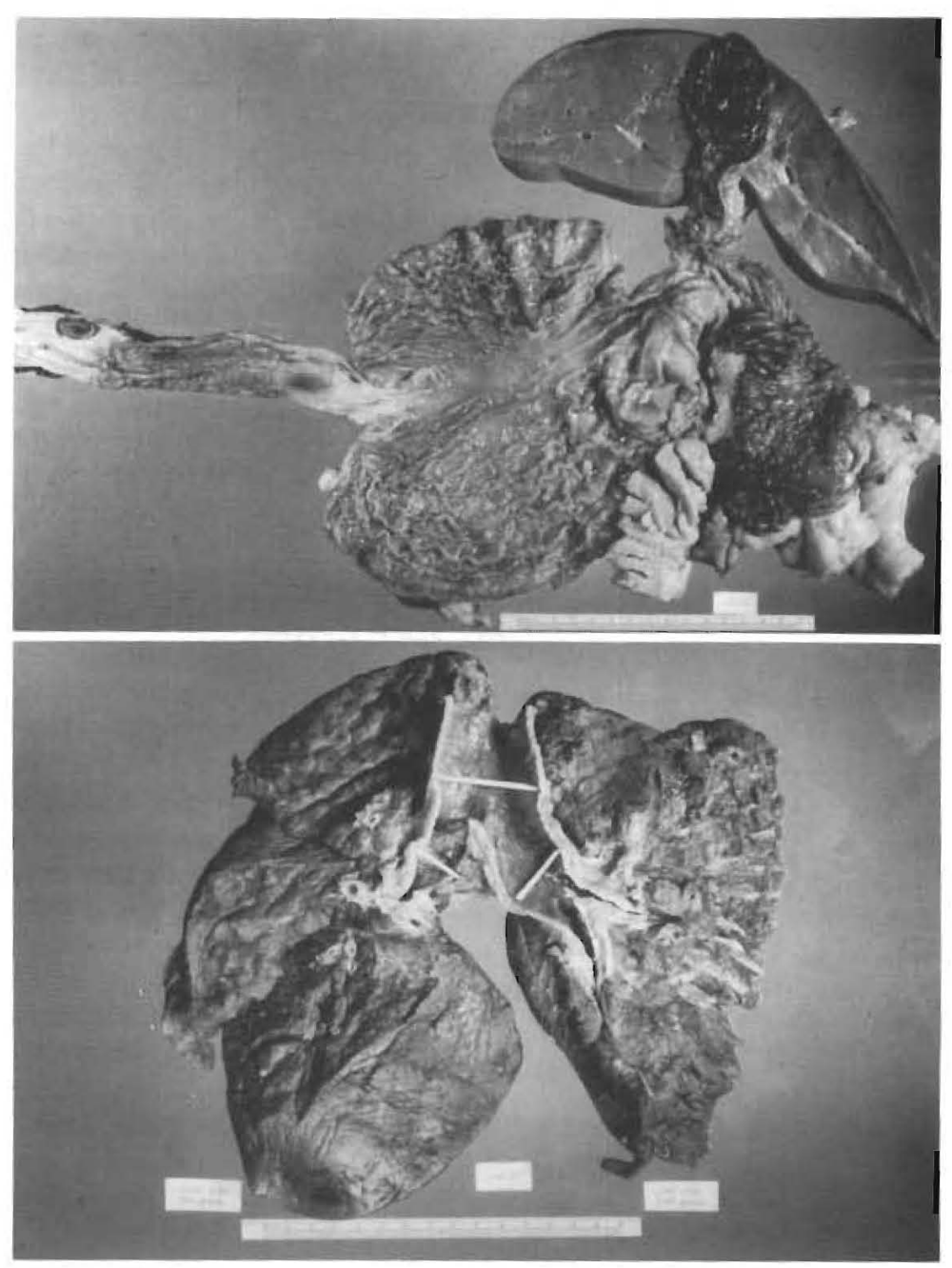
fewer than 70 cases of renal homotransplantation, it was pointed out that gastrointestinal hemorrhage occurred during the early postoperative period in 35 of the first 42 cases (83 per cent). ${ }^{87}$ During that era, meticulous prophylactic postoperative antacid therapy was not being given. Subsequently, the magnitude of the problems has been reduced by providing all patients on immunosuppressive regimens with this kind of preventive antacid treatment. Nevertheless, by 1968 , Penn et al. $^{67}$ recorded eight patients from a total of 184 consecutive renal recipients who had required gastric procedures because of gastroduodenal complications - six with hemorrhage and two with duodenal or gastric perforation.

The problems encountered with the stomach and duodenum under these potentially dangerous circumstances post transplantation will not be exhaustively discussed since they are no different from those that have been described in discussions of steroid therapy in patients who have not undergone transplantation. However, a comment is in order about the appropriate gastric procedure, at least if the complication is hemorrhage. A conservative operative procedure has almost always been performed, consisting of vagotomy and pyloroplasty. In the vast majority of cases, the source of hemorrhage has been superficial ulceration of the gastric mucosa or gastritis, whereas in the remainder, relatively superficial duodenal ulcers have usually been responsible. With vagotomy and pyloroplasty, reoperation and resection for continuing or recurrent hemorrhage has been necessary in only one instance.

In the early days of transplantation, it was assumed that perforation of a hollow viscus was almost tantamount to death. However, it has been learned that simple closure of such a perforation, provided this is carried out early, has a good prospect of success. Even under immunosuppression, the peritoneal cavity can withstand a single insult if it is not of great duration and if it is effectively treated.

\section{COMPLICATIONS AFFECTING THE INTESTINES}

The Small Bowel. By far the most common complication affecting the small bowel in transplant recipients is intestinal obstruction from adhesions. There are several obvious reasons. First, abdominal operations have usually been performed, most frequently to remove the diseased native kidneys or to perform splenectomy. Second, many such recipients have had peritoneal dialysis. Finally, the transplantation itself is sometimes performed intraperitoneally, particularly if the recipient is a child $^{87}$ whose extraperitoneal space cannot easily accommodate an adult organ. Two of our first 10 pediatric patients who had the intraperitoneal homograft placement required reoperation at a later time for lysis of adhesions at the transplantation site.

Occasionally, there may be intrinsic small intestinal lesions. For example, in one of our first recipients of an auxiliary liver homograft diffuse monilial enteritis developed and caused him to bleed to death. ${ }^{88}$ Within the last few months, we have seen a kidney recipient in whom discrete ulcers, apparently also caused by Candida albicans, developed. The condition first led to small bowel perforation, necessitating resection, and within a few weeks massive hemorrhage from a residual ulcer occurred, requiring a second enterectomy. The patient survived both procedures.

The Colon. Of all the gastrointestinal complications after organ transplantation, those affecting the colon have been the most uniformly lethal. The only formal report on this subject in the literature was by Penn et al. $^{63}$ By 1969 they had collected from the University of Colorado case material eight cases of perforated sigmoid diverticulitis, pseudomembranous enterocolitis, granulomatous colitis, ulcerative colitis, or perforation due to an unrecognized iatrogenic injury. All of these patients died. Since that time, a patient with perforated diverticulitis has been successfully treated in two stages, first exteriorization of a perforated sigmoid diverticulum and then closure of the colostomy 6 weeks later. A few other examples of effective treatment of perforating colonic lesions have been reported. ${ }^{17}$

If more survivals are to be obtained when serious inflammatory colonic lesions occur, a high degree of suspicion and early operation will be necessary. In the last 3 years, a half dozen renal patients have been discovered at autopsy to have large ulcers of the cecum. These renal recipients usually had 
diarrhea, frequently accompanied by gramnegative septicemia or intermittent bright red rectal bleeding. Barium enema examinations were normal. For such a syndrome we now believe that exploration and consideration of a right colectomy should be entertained.

In addition to the lethal colonic complications, fecal impaction has been common, so severe in one case that operative relief was eventually necessary. There are reasons for this. Disturbances of bowel activity are common in both renal and hepatic homograft recipients. Before the transplant operation the patient may have a hypomotility syndrome, or even frank ileus, because of uremia. ${ }^{87}$ After transplantation there may be a period of poor graft function, which may perpetuate a preexisting hypomotility state. As soon as the patient can take liquids by mouth he is given large doses of antacids, as described in the preceding section. At times, the nonabsorbable antacid gels may cause constipation or fecal impaction. In order to avoid these problems in organ recipients, the colon is kept empty by preoperative and postoperative enemas, and liberal use is made of stool softeners.

\section{PANCREATIC COMPLICATIONS}

Pancreatitis and Hyperamylasemia. Elevation of the serum amylase is not an unusual finding after either renal or hepatic transplantation. If the patient is asymptomatic and potential etiologic factors can be excluded, the laboratory finding is probably of little significance. However, when clinical signs and symptoms of pancreatitis accompany the biochemical abnormality, the findings become of grave prognostic significance.

The first report of pancreatitis after renal transplantation revealed that this complication developed in three of the first 42 consecutive patients (7.1 per cent) at the University of Colorado. ${ }^{87}$ Subsequently, most major transplant centers, when polled by Johnson and Nabseth, reported one or more cases of acute pancreatitis among their renal recipients. ${ }^{38}$ The incidence in their collected series was 19 cases among 1074 recipients, or slightly less than 2 per cent. However, the true incidence of this compli- cation can easily be demonstrated to be higher, if clinical and biochemical evidence for the diagnosis is systematically sought.

Penn et al. ${ }^{66}$ reviewed 301 consecutive renal homograft recipients; 17 patients (5.6 per cent) were diagnosed as having proven (12 cases) or almost certain (five cases) pancreatitis (Table 2). Eleven of the 12 patients with proven pancreatitis died, and this complication was the major cause or a contributory factor to death in all 11 . The twelfth patient with proven pancreatitis survived, but only after a stormy convalescence (Fig. 16). The five patients with highly probable pancreatitis survived after protracted illnesses.

In addition to the symptomatic cases of pancreatitis, Penn et al. ${ }^{65}$ reported an additional 43 patients (14.3 per cent) who had asymptomatic hyperamylasemia post transplantation (Table 2). Many of these patients, who frequently had had elevations of the serum amylase even before transplantation, probably experienced clinically undetected episodes of pancreatitis at some time in their convalescence, but were apparently not thereby harmed.

The etiology of pancreatitis in transplantation patients is probably complex. Inflammatory changes in the pancreas are common in uremia, ${ }^{7}$ and abnormalities of the gland are frequently noted at the time of bilateral nephrectomy and splenectomy. Operative trauma to the pancreas in the course of the upper abdominal dissection may occasionally aggravate preexisting inflamma-

TABLE 2 INCIDENCE OF PANCREATITIS IN 301 CONSECUTIVE RECIPIENTS OF RENAL HOMOGRAFTS*

\begin{tabular}{lcc}
\hline \multicolumn{1}{c}{ Diagnosis } & \multicolumn{2}{c}{ Patients } \\
\hline Preexisting pancreatitis & 5 & $(1.7 \%)$ \\
& 17 & $(5.6 \%)$ \\
Acute pancreatitis & 12 & \\
Definite & 5 & \\
Suspected & $11 / 17$ & $(64.7 \%)$ \\
Mortality & 43 & $(14.7 \%)$ \\
Hyperamylasemia & 43 \\
\hline
\end{tabular}

*Data from Penn, I., Durst, A. L., and Machado, M., Halgrimson, C. G., Booth, A. S., Jr., Putnam, C. W., Groth, C. G., and Starzl, T. E.: Acute Pancreatitis and Hyperamylasemia in Renal Homograft Recipients. Arch. Surg., 105:167, 1972. 


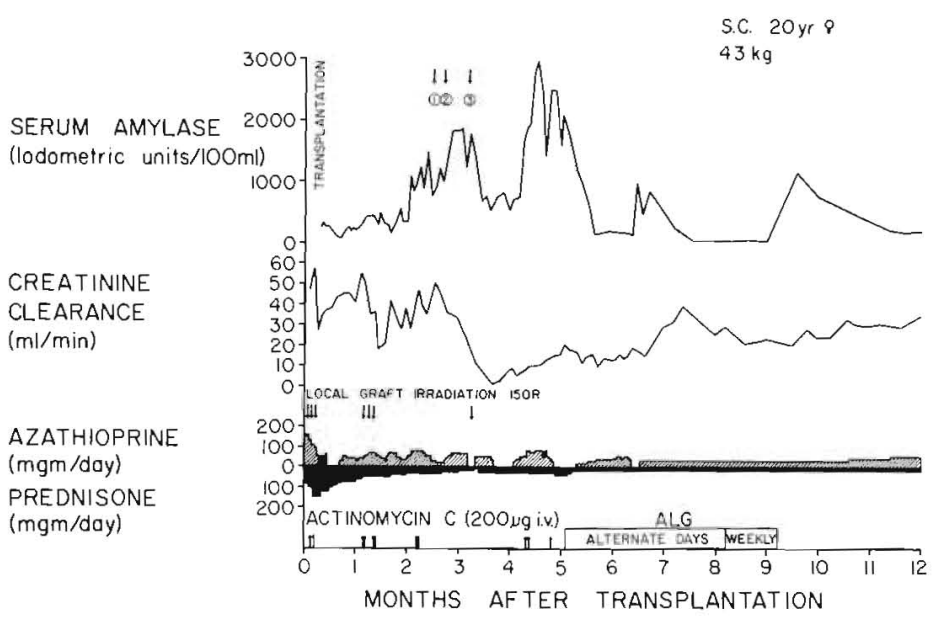

tion or possibly trigger an acute episode of pancreatitis

Hyperparathyroidism and hypercalcemia, which frequently complicate uremia (see later), may in themselves predispose to pancreatitis. Three of the patients with pancreatitis reported by Penn were found to have parathyroid hyperplasia and five of the patients with asymptomatic hyperamylasemia had concomitant elevations of the serum calcium. One of the latter recipients required emergency parathyroidectomy for hyperplasia 46 months post transplantation.

Cholelithiasis, hepatitis, and local or systemic infections with bacteria, fungi, or viruses $^{31}$ may also cause or predispose to pancreatitis and must be carefully excluded. Less easily documented, but probably more commonly of etiologic significance, are drugs administered post transplantation. Those implicated include azathioprine, ${ }^{32}$ corticosteroids, ${ }^{15}$ and the diuretic chlorothiazide. ${ }^{19}$

Finally, renal insufficiency may in itself produce hyperamylasemia by virtue of decreased enzyme clearance. ${ }^{41}$ This last consicleration may partially explain the large number of patients noted to have asymptomatic hyperamylasemia while on dialysis or during episodes of poor renal function post transplantation.

Although preexisting pancreatitis is not of itself a contraindication to renal transplantation, every effort should be made to diagnose and correct predisposing factors, including biliary tract disease and hyperparathyroidism. When the diagnosis is made for the first time after transplantation, efforts are directed toward the correction of inciting factors, vigorous supportive care
Figure 16 Proven pancreatitis in a renal homograft recipient. The pancreatitis was complicated by abscess formation necessitating several surgical procedures. An abscess in the left labium majus was drained 75 days after transplantation (1). Subsequently, a sinogram (Fig. 17) demonstrated an extensive proximal extension of the abscess which was then drained through an incision in the left flank (2). Sixteen days later, a large retroperitoneal abscess communicating with the first two abscesses and arising from the pancreas was drained (3). The serum amylase level remained elevated for a prolonged period. Graft function deteriorated during the treatment of the abscesses but partially recovered. (From Penn, I., et al.: Acute Pancreatitis and Hyperamylasemia in Renal Homograft Recipients, Arch. Surg., 105:167, 1972.)

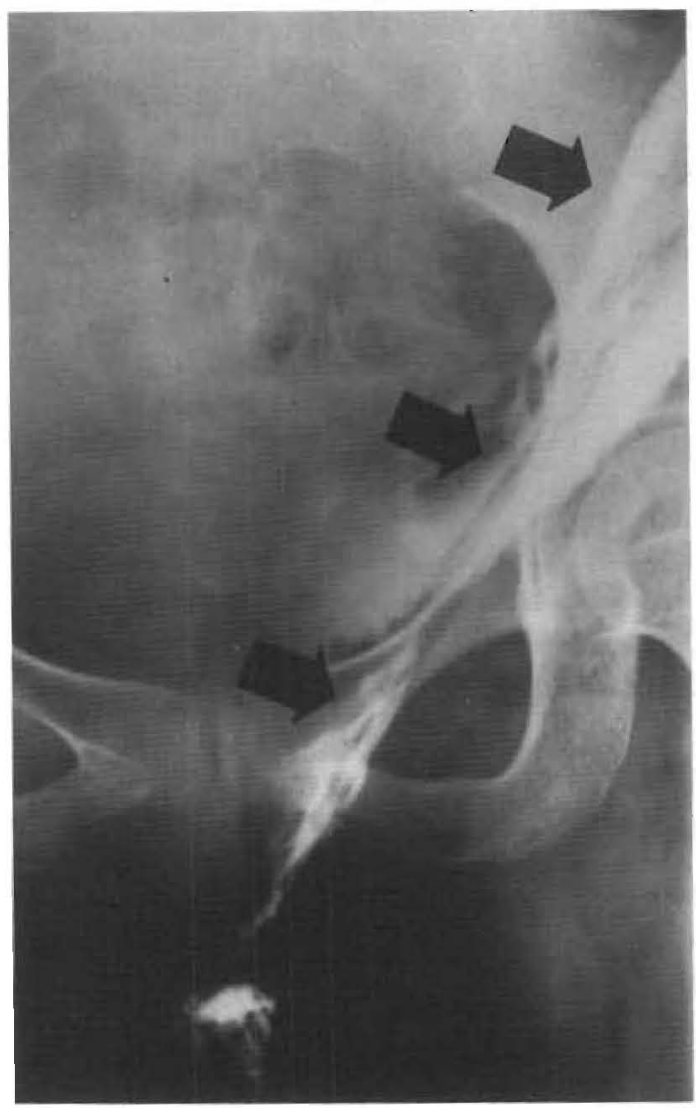

Figure 17 Sinogram taken after drainage of the first abscess in the patient whose course is shown in Figure 16. A tract (arrows) extends from the left labium majus retroperitoneally into the left flank. (From Penn, I., et al.: Acute Pancreatitis and Hyperamylasemia in Renal Homograft Recipients. Arch. Surg., 105:167, 1972.) 
including antibiotic therapy, and the aggressive treatment of complications, such as abscess formation (Fig. 17). Serious consideration should also be given to curtailment of immunosuppression, particularly of the corticosteroid dosage.

Hyperglycemia and Diabetes Mellitus. About one-third of nondiabetic patients awaiting renal transplantation manifest hyperglycemia, usually without glycosuria. The elevated blood sugars are usually a manifestation of the glucose intolerance of uremia and are of little clinical significance.

After renal transplantation, more than half of all recipients will have hyperglycemia of varying severity. ${ }^{87}$ In some patients, the biochemical abnormality simply reflects periods of poor renal function from whatever cause and is probably of no greater significance than in the uremic patient who has not undergone transplantation. More commonly, however, the blood sugar elevations parallel temporally the administration of large doses of corticosteroids. The phenomenon is dose-related, usually having its onset when the dose exceeds $2.5 \mathrm{mg}$. per kilogram per day and usually resolving when the dose falls below $0.7 \mathrm{mg}$. per kilogram per day. ${ }^{65}$ In about 15 per cent of patients (Table 3 ), the hyperglycemia is severe enough to require treatment, and in a few instances prodigious doses of insulin may be required to achieve even mediocre control of the fast-

TABLE 3 POSTTRANSPLANTATION HYPERGLYCEMIA*

\begin{tabular}{|c|c|c|}
\hline & Patients & Mortality \\
\hline $\begin{array}{l}\text { Severe hyperglycemia, } \\
\text { requiring pharmacologic } \\
\text { therapy } \\
\text { Hyperglycemia }>30 \text { days, } \\
\text { but not requiring } \\
\text { treatment }\end{array}$ & $44(14.6 \%)$ & $55 \%$ \\
\hline Intermittent hyperglycemia & $52(17.3 \%)$ & \\
\hline $\begin{array}{l}\text { Occasional hyperglycemic } \\
\text { episodes }\end{array}$ & $53(17.6 \%)$ & $36.5 \%$ \\
\hline Euglycemia & $\frac{136}{301}(45.2 \%)$ & \\
\hline
\end{tabular}

*From Penn, I., Durst, A. L., and Machado, M.: Diabetes and Hyperglycemia in Renal Homograft Recipients. In preparation. ing blood glucose level. More frequently, the hyperglycemia is less severe, transient, or intermittent and requires no specific therapy other than attention to dies. In these milder cases of diabetes, resolution occurs with reduction in steroid therapy, as mentioned previously.

Not surprisingly, the mortality among patients manifesting hyperglycemia is greater than that among those recipients maintaining euglycemia (Table 3). Although an occasional patient may die as a direct result of a diabetic complication such as ketoacidosis, the vast majority of these deaths cannot be attributed directly to hyperglycemia or frank diabetes. Instead, the most frequent cause of death is found to be sepsis, again reflecting the necessity for large-dose steroid administration to combat poor renal function.

Nonetheless, the development of hyperglycemia in a previously euglycemic recipient or of ketoacidosis in the previously well controlled diabetic recipient calls for a vigorous diagnostic evaluation. This should include frequent assessments of renal function and a careful search for infectious complications which might initially otherwise pass unnoticed. Concomitantly, vigorous treatment with dietary control, oral hypoglycemic agents, or insulin should be undertaken to reestablish euglycemia, since ketoacidosis may rapidly become life-threatening.

In view of the adverse implications of diabetes mellitus diagnosed for the first time post transplantation, is it reasonable to recommend transplantation for patients whose uremia was caused by diabetic nephropathy? Recently Najarian and his associates at the University of Minnesota have attempted cadaveric renal transplantation in about two dozen patients with diabetes mellitus. Although the results remain distinctly inferior to those in comparable recipients treated for other renal diseases, the prognosis is nonetheless considerably better than that for diabetics on chronic dialysis who almost never survive for as long as 2 years. It would therefore seem that diabetes mellitus could, and should, be removed from the list of contraindications to renal transplantation and the prospective diabetic recipient reevaluated in light of this more recent experience. Our own experience supports that of Najarian. 


\section{HEPATIC COMPLICATIONS}

At some time postoperatively, the majority of renal homograft recipients manifest abnormalities of one or more of the standard liver function tests. The immunosuppressive program is presumably responsible for the high incidence of the liver dysfunction, either because of drug hepatotoxicity or because the consequent weakening of the host immune system permits the frequent development of viral hepatitis. The differential diagnosis of hepatotoxicity from hepatitis after transplantation is usually difficult and frequently impossible. Penn's ${ }^{68}$ studies have demonstrated the extreme frequency with which such a perplexing distinction should be made, and Torisu et al. ${ }^{105}$ have shown how often this may not be possible with any diagnostic tool currently available.

Penn et al. ${ }^{68}$ examined the preoperative and postoperative liver function tests in 146 renal recipients. At some time post transplantation, abnormalities in the serum bilirubin, alkaline phosphatase, SGOT, SGPT, prothrombin time, serum protein concentrations, or sulfobromophthalein (BSP) clearance developed in 88 (60 per cent) of the patients. The hepatic dysfunction usually appeared within the first 6 postoperative months (Fig. 18). In most instances the changes were transient and mild. These were accompanied by clinical complaints in only a small minority. In 20 patients, however, the derangements of liver function were severe and persistent; four of the recipients died of hepatic failure 5 to 18 months after transplantation.

It is of some interest that in the series reported by Penn et al. ${ }^{68}$ the 66 patients treated with the triple-drug regimen of azathioprine, prednisone, and heterologous antilymphocyte globulin had a somewhat lower incidence (54 per cent) of hepatic dysfunction than the 80 patients who received only azathioprine and prednisone (65 per cent). Moreover, all four of the fatalities were in the group receiving double-drug therapy. It was concluded that the magnitude of the problem had been less since the addition of ALG to the immunosuppressive regimen, probably because of concomitant reductions in steroid and azathioprine dosage.

The Question of Drug HepatotoxICITY. The two drugs, azathioprine and prednisone, commonly employed in modern immunosuppressive programs are known to be potentially toxic to the liver, as discussed previously. The main attention has been paid to the hepatotoxicity of azathioprine. However, the diagnosis of azathioprine hepatotoxicity in patients has been made with certainty in only a few dramatic cases in which the events of hepatic dysfunction correlated temporally with the duration of or increases in azathioprine dosage. One such case is depicted in Figure 19. Nevertheless, when biochemical or clinical evidence of hepatic injury develops in the renal recipient receiving azathioprine, hepatotoxicity should be suspected and consideration given to modification of the immunosup-

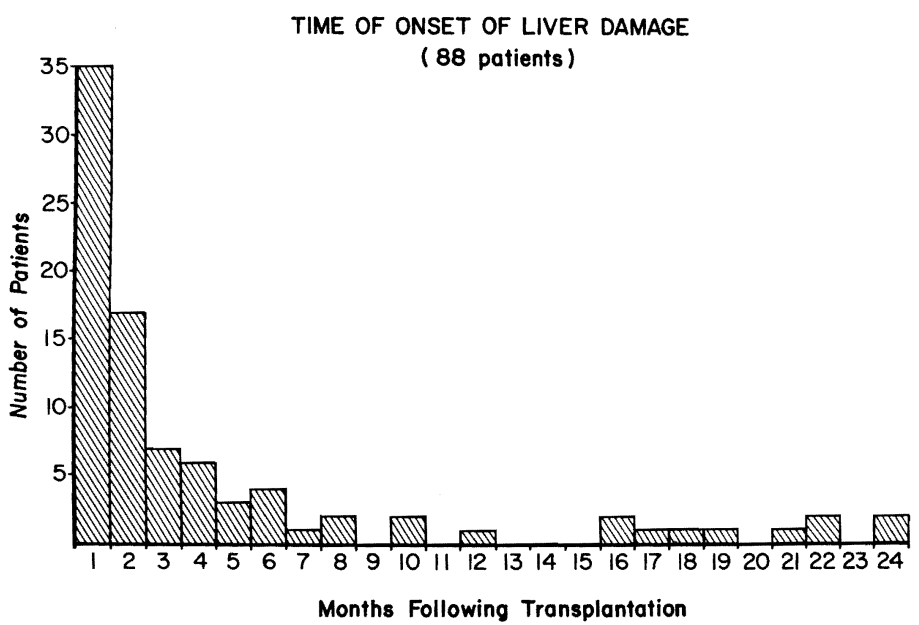

Figure 18 Time of onset in human renal transplant recipients of abnormalities of one or more liver function tests. One hundred forty-six patients were studied. Of these, 88 (60 per cent) had some evidence of hepatic damage, usually during the first 6 postoperative months. This was usually mild, but in 20 patients (14 per cent) it was severe. (From Penn, I. et al.: Hepatic Disorders in Renal Homograft Recipients. Current Topics in Surgical Research, 1:67, 1969.) 


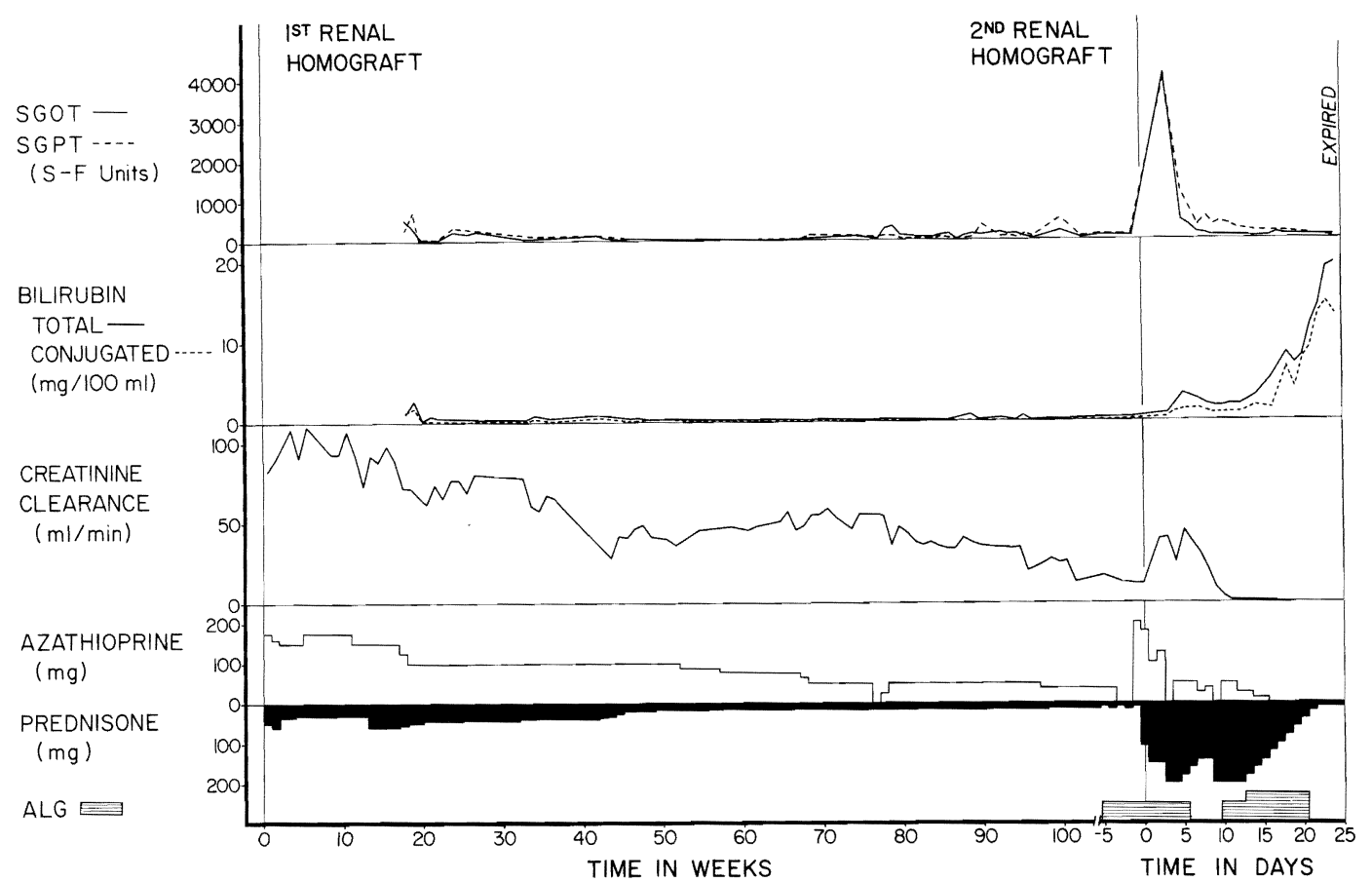

Figure 19 The course of a kidney transplant recipient who appeared to have suffered liver damage from azathioprine toxicity. About 5 months after his first renal homotransplantation, low-grade jaundice developed and increases in transaminase levels were seen. The azathioprine dose was cut immediately and further reductions were made at subsequent intervals. The homograft eventually failed and was removed after about 2 years. When retransplantation was performed, four large doses of azathioprine were given just before and after operation. Immediately, the transaminases rose to more than 4000 units. The patient became intensely jaundiced and died of hepatic and renal failure. (From Starzl, T. E.: Experience in Hepatic Transplantation. Philadelphia, W. B. Saunders Company, 1969.)

pressive program, as will be discussed later.

Hepatitis. With the development of serologic tests for the detection of hepatitisassociated antigen (HAA) - also termed the Australia (Au) or the hepatitis B ( $\mathrm{HbAg}$ ) antigen - it became possible to test with some precision the hypothesis that at least some of these cases of liver damage occurring during treatment with dialysis or after renal transplantation were due to serum hepatitis.

In 1964 Blumberg and his associates reported the discovery of a foreign substance in the serum of Australian aborigines (hence the term "Australia antigen"). The particle was subsequently identified in the blood of patients with leukemia, Down's syndrome, leprosy, and serum hepatitis. Prince $^{74}$ of New York reported in 1968 a similar antigen in the blood of patients with -serum hepatitis (hepatitis B). The two substances were soon shown to be serologically identical and have been termed the hepatitis $\mathrm{B}$ antigen ( $\mathrm{HbAg}$ ).

The nature of the hepatitis $\mathrm{B}$ antigen par- ticle and its relationship to the serum hepatitis virus have only recently been clarified. ${ }^{\mathbf{5 0}}$ Several particles varying in size and in the presence or absence of an RNA core have been isolated and identified by electron microscopy of liver tissue and centrifugates of sera, as summarized in Table 4.

The current hypothesis holds that the Huang particle represents the RNA-containing (or, possibly, DNA-containing) viral core which infects the hepatocyte nucleus. ${ }^{50}$ There it replicates and inflicts the liver cell damage associated with serum hepatitis. The viral cores generated within the nucleus by replication migrate to the cytoplasm where they become ensheathed with protein coats to form Dane particles. ${ }^{16}$ For unknown reasons, the cytoplasmic messenger RNA directs the production of protein coats (the $\mathrm{HbAg}$ ) a millionfold or more in excess of that required for the number of viral cores present. The excess coats enter the blood stream and there can be readily detected as $\mathrm{Hb}$ antigenemia, but are not infective. A few Dane particles, containing a viral core 
TABLE 4 PARTICLES DISCOVERED BY ELECTRONMICROSCOPY IN THE SERUM OR HEPATOCYTES OF PATIENTS WITH HEPATITIS B*

\begin{tabular}{llccc}
\hline \multicolumn{1}{c}{ Discoverer } & \multicolumn{1}{c}{ Location } & Size & $\begin{array}{c}\text { DNA or } \\
\text { RNA Core }\end{array}$ & Identity \\
\hline $\begin{array}{l}\text { 1. Bayer, Prince } \\
\text { and others }\end{array}$ & Serum & $20 \mathrm{~nm}$. diam. & No & $\mathrm{Au} \mathrm{Ag}$ \\
2. Many & Serum & $\begin{array}{c}20 \mathrm{~nm} \text {. diam. length } \\
2-3 \times \text { that of }(1)\end{array}$ & No & $\begin{array}{c}\text { Another form of Au } \\
\text { Ag }\end{array}$ \\
3. Dane & $\begin{array}{l}\text { Serum and cytoplasm } \\
\text { of hepatocytes }\end{array}$ & $42 \mathrm{~nm}$. diam. & Yes & $\begin{array}{c}\text { Viral core }+\mathrm{Au} \mathrm{Ag} \\
\text { coat }\end{array}$ \\
4. Huang and others & Nuclei of hepatocytes & $23-27 \mathrm{~nm}$. diam. & Yes & Viral core \\
\hline
\end{tabular}

*Data from Maugh, T. H., II: Hepatitis: A New Understanding Emerges. Science, 176: 1225, 1972.

within the protein coat, and therefore infective, also enter the circulation.

During an attack of hepatitis B, antibodies form against both the core and the protein coat. The antibodies against the former persist, frequently for as long as 2 years and are thought to be protective, while the antibodies against the protein coat, at least in the nonimmunosuppressed patient, usually disappear as soon as the $\mathrm{HbAg}$ is cleared from the system..$^{50}$

Working with infectious human sera positive for HbAg, Purcell and others have succeeded in transmitting subclinical hepatitis to rhesus monkeys and chimpanzees, adding further support to the contention that the $\mathrm{HbAg}$ is intimately associated with the serum hepatitis virus..$^{50}$

The appearance of the Australia antigen in the blood stream of a transplant recipient, either preoperatively or in the post- transplantation period, does not necessarily have an unfavorable prognostic significance in individual cases (Table 5). ${ }^{105}$ Thus, it would not seem reasonable to forbid renal transplantation to a potential recipient merely because of a positive Au serology. Nonetheless, screening for $\mathrm{Au}$ antigen should be a part of the transplant recipient (and donor) workup, since documentation of Au positivity has certain practical implications.

First, the finding should prompt a careful evaluation of hepatic function, which, if abnormal, should probably include liver biopsy. If chronic aggressive hepatitis proves to be the diagnosis, the propriety of transplantation should be reconsidered.

Secondly, the patient found to have Australia antigen must be regarded as a hepatitis carrier and should be managed as such. Precautions entail proper techniques of iso-

TABLE 5 LACK OF CORRELATION OF AUSTRALIA ANTIGENEMIA AND HEPATIC DYSFUNCTION IN 45 PATIENTS WHO HAD FREQUENT DETERMINATIONS OF LIVER FUNCTION AND IN WHOM SEROLOGIC EVIDENCE FOR AUSTRALIA ANTIGEN OR ANTIBODY WAS SOUGHT*

\begin{tabular}{lccccc}
\hline & $\begin{array}{c}\text { Number of Patients } \\
\text { Studied }\end{array}$ & None & Minor $\dagger$ & Major $\neq$ & $\begin{array}{c}\text { Deaths } \\
\text { Attributable to } \\
\text { Liver Disease }\end{array}$ \\
\hline Au + by all tests & 12 & 5 & 6 & 1 & 0 \\
Au + by complement fixation only & 7 & 4 & 2 & 1 & 0 \\
Au negative & 24 & 10 & 9 & 5 & 3 \\
Anti-Au antibody & 2 & 1 & 0 & 1 & 1 \\
\hline
\end{tabular}

*Data from Torisu, M., Yokoyama, T., Amemiya, H., Kohler, P. F., Schroter, G., Martineau, G., Penn, I., Palmer, W., Halgrimson, C. G., Putnam, C. W., and Starzl, T. E.: Immunosuppression, Liver Injury, and Hepatitis in Renal, Hepatic, and Cardiac Homograft Recipients: With Particular Reference to the Australia Antigen. Aun. Surg., 174:620, 1971 .

$\dagger$ Minor elevations in the serum transaminases (50-250 I.U.).

$\$$ Elevations of the transaminases $>250 \mathrm{I} . \mathrm{U}$. and/or bilirubin $>2 \mathrm{mg} . / 100 \mathrm{ml}$. 
lation, including stool and needle precautions, and education of paramedical personnel. Several transplantation centers have already reported deaths from hepatitis among their nurses, technicians, and other personnel. ${ }^{105}$ In this regard, the healthy physician, nurse, technician, or relative is probably at greater risk of developing immediately fatal liver disease than the chronically ill or immunosuppressed dialysis or transplant patient, whereas the prospects of having chronic liver disease have seemed to us much greater in the population under immunosuppression.

Finally, efforts should be made to protect the transplant recipient from unnecessary exposure to hepatitis, such as by HbAg-positive blood products. Au antigen tests should also be performed on all prospective organ donors. Several cadaveric donors who have been pronounced dead in our hospitals on the basis of irreversible neurologic injury have been discovered to have high titer Au antigenemia. If this had not been detected in time, several organs would have been transplanted from each donor with the virtual certainty of transfer of the hepatitis virus to the recipients.

MODIFICATION OF THE IMMUNOSUPPRESsive Regimen in the Presence of Hepatic Complications. In the patient with moderate or severe hepatic dysfunction post transplantation or in whom azathioprine hepatotoxicity is suspected-usually on the basis of progressive hepatic disease in the face of a negative result in the search for Australia antigen - consideration should be given to drastic modifications of the immunosuppressive program. Zarday et al. ${ }^{113}$ have recommended that in these circumstances azathioprine be discontinued entirely and that the patient be maintained only with steroids.

Alternatively, substitution of cyclophosphamide (Cytoxan) for azathioprine in the immunosuppressive regimen has been carried out. ${ }^{101}$ As mentioned previously, cyclophosphamide when used in low doses has little if any hepatotoxicity. The course of a patient in whom such a switch in therapy was made is shown in Figure 20. This girl developed fever and extremely severe hepatic dysfunction, including jaundice, while under treatment with azathioprine (Imuran) and prednisone. It was feared at the time that she was dying of liver disease, and cyclophosphamide was substituted for the suspected guilty agent, azathioprine. She completely recovered after the change in therapy and remained well for about 1 year. At that time, azathioprine was restored to the regimen and there was recurrence of high fever, jaundice, and many of the same symptoms that had been present during the previous course of azathioprine. These were all promptly relieved by switching once more to cyclophosphamide.

Among our outpatients being followed

$41 \rightarrow 48 \mathrm{Kg}$

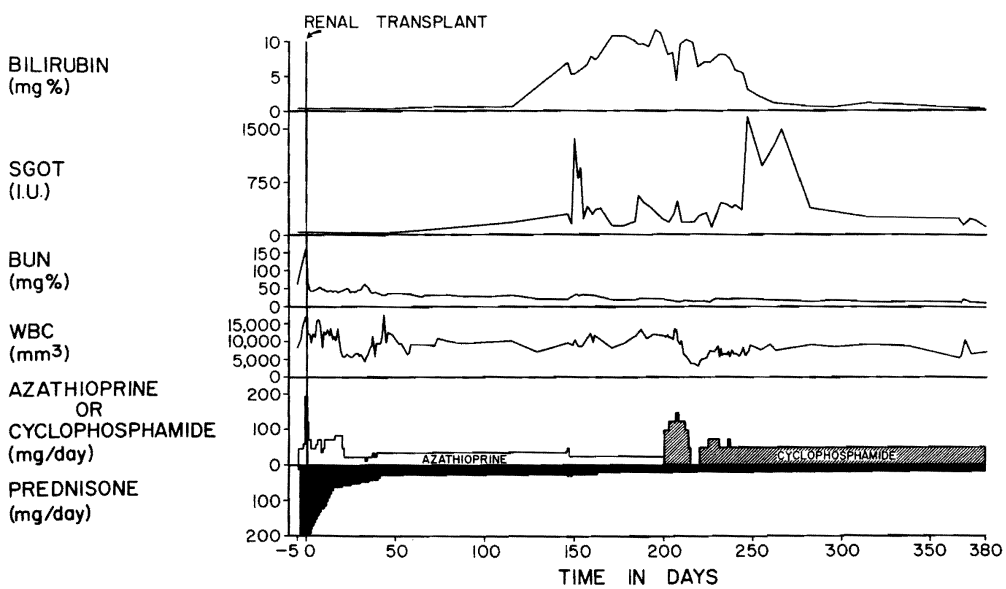

Figure 20 The course of a 17-year-old female in whom azathioprine was stopped because of the suspicion of hepatotoxicity. Multiple Australia-antigen tests for serum hepatitis were negative. Note the recession of jaundice after the substitution of cyclophosphamide for azathioprine. (From Starzl, T. E., et al.: Cyclophosphamide and Whole Organ Transplantation in Humans. Surg., Gynec. \& Obst., 133:981, 1971. By permission of Surgery, Gynecology \& Obstetrics.) 
TABLE 6 INCIDENCE* OF AU ANTIGEN BY RANDOM SINGLE SAMPLING IN HOMOGRAFT RECIPIENTS FROM ONE MONTH TO 8 YEARS AFTER OPERATION, USING IMMUNODIFFUSION OR ELECTRO-IMMUNODIFFUSION TESTS FOR SCREENING

\begin{tabular}{cccc}
$\begin{array}{c}\text { Number } \\
\text { of Patients }\end{array}$ & $\begin{array}{c}\text { Au Antigen } \\
\text { Positive }\end{array}$ & $\begin{array}{c}\text { Anti-Au } \\
\text { Antibody }\end{array}$ & $\begin{array}{c}\text { Negative } \\
\text { for Au Antigen } \\
\text { and Antibody }\end{array}$ \\
\hline & & & \\
89 & $15(16.9 \%)$ & $2(2.2 \%)$ & $72(80.9 \%)$
\end{tabular}

*The incidence was actually higher than shown since several additional cases were detected within the negative group by the more sensitive method of complement fixation.

†From Torisu, M., Yokoyama, T., Amemiya, H., Kohler, P. F., Schroter, G., Martineau, G., Penn, I., Palmer, W., Halgrimson, C. G., Putnam, C. W., and Starzl, T. E.: Immunosuppression, Liver Injury, and Hepatitis in Renal, Hepatic, and Cardiac Homograft Recipients: With Particular Reference to the Australia Antigen. Amm. Surg., 174:620, 1971.

for up to more than a decade after renal transplantation, there are about two dozen recipients who have chronic Australia antigenemia (Table 6). Once this serologic finding develops in the immunosuppressed recipient, it does not go away if it is detectable by the Ouchterlony method or other techniques based on the antigen-antibody precipitation principle. We have concluded that the treatment with immunosuppression has modified the natural course of the serum hepatitis, that no specific treatment is feasible, and that the best thing to do is to try to prevent these patients from transmitting the disease to their family members or others.

\section{HYPERPARATHYROIDISM AND BONE DISEASE}

The complication of hyperparathyroidism after transplantation is an example of a disorder to the etiology of which preexisting renal failure, as well as the side effects of immunosuppressive agents, are presumed to make important contributions. To begin with, secondary hyperparathyroidism is present in most patients with chronic renal failure. From autopsy studies, it has been known for nearly half a century that parathyroid hyperplasia is a common finding under these circumstances. The patho- genesis of the parathyroid lesion has been relatively well defined. ${ }^{10,76}$ With advanced renal disease and failure of phosphate excretion, hyperphosphatemia develops, with consequent depression of serum calcium. In turn, the hypocalcemia is an effective stimulus for parathyroid hyperplasia and presumably for heightened parathyroid hormone production and release.

It is into this environment that many renal homografts are placed. Since the early days of renal homotransplantation, it has been thoroughly appreciated that the secondary hyperparathyroidism persists into the immediate postoperative period.51, 72, 82 Unfortunately, it has also been accepted by most of these investigators that resolution of this hyperparathyroidism occurs promptly and almost universally, $3,36,37$ especially if high serum calcium values are treated with phosphate-containing antacids such as Phosphaljel. With conservative management, severe hypercalcemia post transplantation has been uncommon, and the dogma has become well established that parathyroidectomy is very seldom required.

The information generated from this center in the last 2 years ${ }^{23}$ has caused us to alter this conservative position. Although the exact incidence of hyperparathyroidism after transplantation cannot yet be accurately stated from our case material, it now appears to be at least 20 per cent. The insidious feature of the complication has been its occult and subtle nature, which in some instances, particularly in children, has permitted progressive bone changes to create a pariah without the features of biochemically florid hyperparathyroidism ever having been demonstrated.

Some of the characteristics of this kind of hyperparathyroidism in 18 patients treated in the last year and a half at the University of Colorado are shown in Table $7{ }^{23}$ Before transplantation, all of these recipients had suffered from renal failure for at least several years and all but one had required hemodialysis. There was radiographic evidence of bone disease in 17 of the 18 patients, invariably including osteoporosis. However, 10 also had radiographic or biopsy evidence of osteitis fibrosis cystica or extraskeletal calcification of the arteries or soft tissues or both. 
TABLE 7 CLINICAL DATA ON EIGHTEEN RENAL TRANSPLANT RECIPIENTS AFTER PARATHYROIDECTOMY*

\begin{tabular}{|c|c|c|c|c|c|}
\hline \multirow{3}{*}{$\begin{array}{l}\text { Age } \\
\text { (yrs.) }\end{array}$} & \multirow{3}{*}{$\begin{array}{l}\text { Creatinine Clearance } \\
\text { after Transplantation } \\
\text { (ml./min.) }\end{array}$} & \multirow{3}{*}{$\begin{array}{c}\text { Interval between } \\
\text { Transplantation } \\
\text { and Parathyroidectomy } \\
\text { (mos.) }\end{array}$} & \multicolumn{3}{|c|}{ Radiographic Findings before Parathyroidectomy } \\
\hline & & & \multicolumn{2}{|c|}{ Bone Disease } & \multirow{2}{*}{$\begin{array}{l}\text { Extra-Skeletal } \\
\text { Calcification }\end{array}$} \\
\hline & & & Osteoporosis & Osteitis Fibrosa & \\
\hline 41 & 95 & 2 & + & - & vascular \\
\hline 22 & 70 & 7 & - & - & - \\
\hline 21 & 81 & 14 & + & - & vascular \\
\hline 10) & 55 & 18 & + & - & vascular \\
\hline 39 & 49 & 20 & + & - & - \\
\hline 43 & 90 & 32 & + & + & soft tissue \\
\hline 27 & 54 & 47 & + & $-\dagger$ & vascular, skin \\
\hline 30 & 90 & 54 & + & - & - \\
\hline 17 & 50 & 63 & ++ & - & vascular, soft tissue \\
\hline 13 & 51 & 53 & + & - & - \\
\hline 30 & 53 & 6 & + & + & - \\
\hline 48 & 89 & 6 & - & + & vascular \\
\hline 32 & 64 & 18 & $+\ddagger$ & - & - \\
\hline 11 & 46 & 19 & + & + & soft tissue \\
\hline 39 & 74 & 39 & + & - & - \\
\hline 24 & 87 & 44 & + & - & - \\
\hline 40 & 75 & 2 & + & $-\dagger$ & vascular \\
\hline 39 & 71 & 12 & $+末$ & - & - \\
\hline
\end{tabular}

*From Geis, W. P., Popovtzer, M. M., Corman, J. L., Halgrimson, C. G., Groth, C. G., and Starzl, T. E.: The Diagnosis and Treatment of Hyperparathyroidism after Renal Homotransplantation. Surg., Gynec. E Obst., 137: 997, 1973. By permission of Surgery, Gynecology E Obstetrics.

$\dagger$ Osteitis fibrosa cystica histologically.

† Aseptic necrosis femoral head.

+ Presence of radiographic bone disease.

- Absence of radiographic bone disease.

The very serious bone complications in such patients may lead to the kind of tragic disabilities shown in Figure 21, with bilateral aseptic necrosis of the femoral neck. The presence of such femoral lesions does not ipso facto make the diagnosis of persistent hyperparathyroidism, although it should arouse suspicion and call for a workup to rule out this diagnosis.

Unfortunately, the determination of total serum calcium and phosphorus concentrations in the renal transplant patient may not provide adequate screening for the diagnosis. In the 18 cases shown in Table 7 , if an elevation in total serum calcium were a prerequisite for the diagnosis, eight of the 18 cases of hyperparathyroidism would never have been identified. In our clinics, heavy reliance has been placed in the recent past upon determination of the ionized calcium. This measurement has provided the decisive clue in every case in which it has been performed. ${ }^{23}$

In much of the older literature, the high incidence of osteoporosis and other bone abnormalities in the renal transplant recipient was attributed to chronic therapy with prednisone. This concept undoubtedly has validity. Steroids have the intrinsic capability of causing osteoporosis. In addition, the steroids may contribute to the perpetuation of preexisting hyperparathyroidism. When steroids are administered, they have a depressant effect upon serum calcium concentration $^{39,45}$ and probably a consequent stimulatory effect upon parathyroid hormone induction. ${ }^{109}$ Thus, paradoxically, the steroids may help control hypercalcemia at the price of setting up a vicious cycle aggravating hyperparathyroidism.

So far, the indications for parathyroidectomy after renal transplantation have undoubtedly been too restrictive. It is also clear that trying to avoid this operation by chronic phosphate administration (as with the use of the antacid Phosphaljel) are selfdefeating. If used for long periods of time, the phosphate therapy may itself recreate the parathyroid stimulus by driving down the serum calcium concentration, or it could 


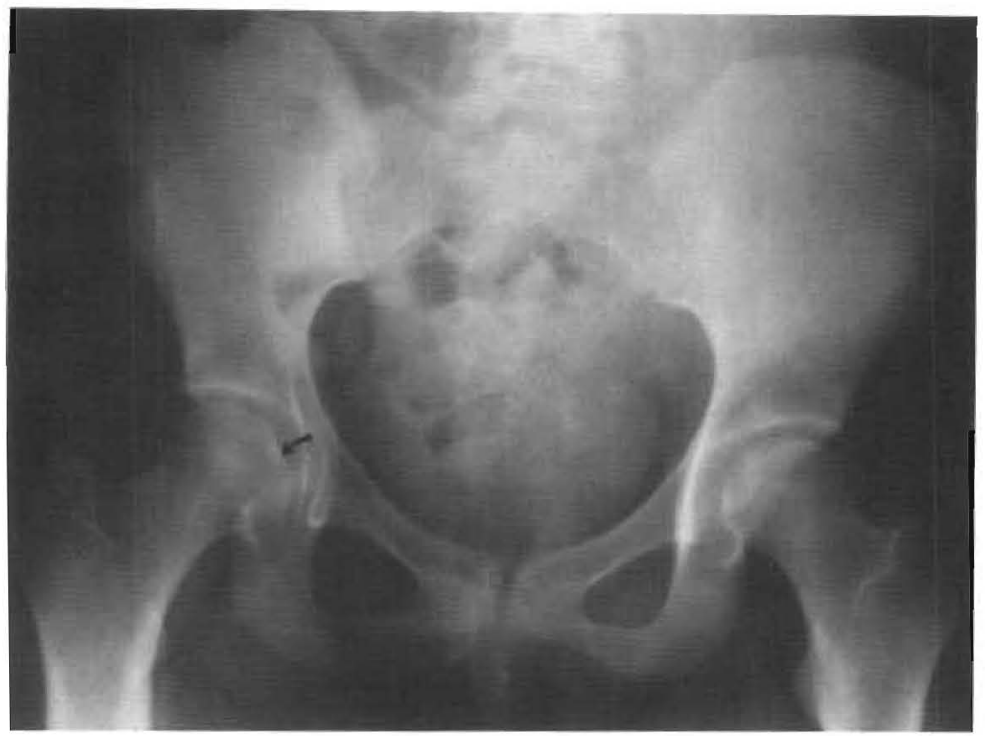

Figure 21 Appearance of aseptic necrosis of the femoral head (arrow) in a young woman after transplantation. She was on prednisone therapy at the time of this delayed complication. (From Starzl, T. E., et al.: Renal Homotransplantation: Late Function and Complications. Ann. Int. Med., $61: 470,1964$.

even, theoretically, aggravate soft tissue calcification. ${ }^{45,}{ }^{109}$ Consequently, parathyroidectomy should be carefully considered after a 3-month period of conservative treatment if there is recurrence of the hyperparathyroid state after phosphate is stopped. The impetus to proceed should be increased if there are serious bone complications in the background or if there is unexplained deterioration of renal homograft function.

It is of interest that almost two-thirds of the patients reviewed in Table 7 had deteriorating renal function prior to parathyroidectomy for hyperparathyroidism. After operation, this decline was either halted or, in almost half the cases, reversed.

In ordinary clinical practice, hyperparathyroidism is usually due to the presence of an adenoma. In contrast, the diagnosis in the renal transplantation patient is almost always diffuse hyperplasia. At operation, before proceeding with resection, it is necessary to identify all the parathyroid glands. After this has been done, a gland with an easily identifiable discrete arterial supply is subtotally amputated with a razor or scalpel, with a small remnant left intact on the vascular stalk. Bleeding from the raw surface is controlled with vascular suture or cautery. Only after the viability of this remnant is established visually are the other glands completely excised. If an accident occurs to the remains of the original gland, additional opportunities would thereby remain available until the last possible moment.

An alternative method of treatment is to excise all the parathyroid tissue and then carry out free autotransplantation of one fragment into the sternocleidomastoid or some other convenient muscle. This technique, which has been extensively reviewed by Alveryd, ${ }^{4}$ has the major advantage that it permits precise determination, by simple metabolic studies carried out within the first few postoperative days, of whether all the glands have been identified. If all glands were found and removed, the tubular phosphate reabsorption (TRP) will become 100 per cent within a few days. Failure to demonstrate this finding signifies that the procedure was incomplete and that at least one gland was left behind. After 4 or 5 days, TRP begins to be restored and, in our experience with nine autotransplantations, satisfactory parathyroid function returns. These nine patients are being studied to make sure that the cicatricial capsule around the established autograft does not, in the long run, squeeze off the blood supply many months or even years later. Consequently, it is our plan to carefully follow the nine patients so far treated with autotransplantation for several years before doing more such procedures. Until then, subtotal parathyroidectomy will continue to be done.

In this chapter, disproportionate atten- 
tion has been given to the complication of hyperparathyroidism for a simple reason. The metabolic consequences of this complication have proved to be truly devastating to some of our patients who have been followed for almost as long as a decade. By the time it was realized that this process was going on, irreparable damage had been done to their skeletons, particularly in patients in the pediatric age group, and it is suspected that permanent harm was also done to the renal homograft itself in some cases.

\section{PROBLEMS OF GROWTH}

In children with chronic uremia, there is usually a failure of growth. After successful transplantation, the growth retardation associated with the original disease is replaced by whatever inhibition is caused by the administration of large doses of steroids. Thus, a growth spurt does not ordinarily occur early after renal homotransplantation, and Najarian and his associates ${ }^{57}$ concluded that catch-up growth in pediatric patients was not to be expected. However, their observations were based on follow-ups that were, for the most part, no greater than 2 years.

In contrast, our own experience with pediatric patients has been that catch-up growth may be seen an extraordinarily long time after transplantation, even after a delay of as long as 2 to 5 years. ${ }^{46}$

\section{PULMONARY DISEASES}

After transplantation of any of the major organs, including the kidney, liver, heart, and pancreas, a major source of subsequent morbidity has been the lung. Pulmonary complications have ranked as either the leading or the second most important cause of death with different reported series of these various kinds of organ transplantation. A very complete analysis of the role of the lung in the deaths of 60 of our early renal transplants has been published by Hill et al. ${ }^{30}$ The complications to which the lung is subject in the immunosuppressed organ recipient include infection, thromboembolization, and neoplasia.

Pneumonitis. As emphasized earlier, the price for success after organ transplantation under immunosuppression is a partial loss of immunologic surveillance. The most dramatic consequence may be infection. In concept, until about a decade ago, many people conceived the problem to be insoluble, as depicted in Figure 22. The suggestion was that measures to prevent the rejection of grafts would inevitably permit the overgrowth of the contemporaneously present bacteria. The pessimism of this view has been thoroughly disproved. Nevertheless, the margin of safety between therapeutically desirable and lethal immunosuppression may not be great, and in some cases it may not exist at all. As far as the lung is concerned, the margin may be broadened by the clever management of pulmonary infectious complications.

Figure 22 Graphic depiction of how immunosuppression, while permitting acceptance of the homograft, may allow the development of infection through a partial loss of immunologic surveillance. (From Starzl, T. E., et al.: Factors in Successful Renal Transplantation. Surgery, 56:296, 1964.)

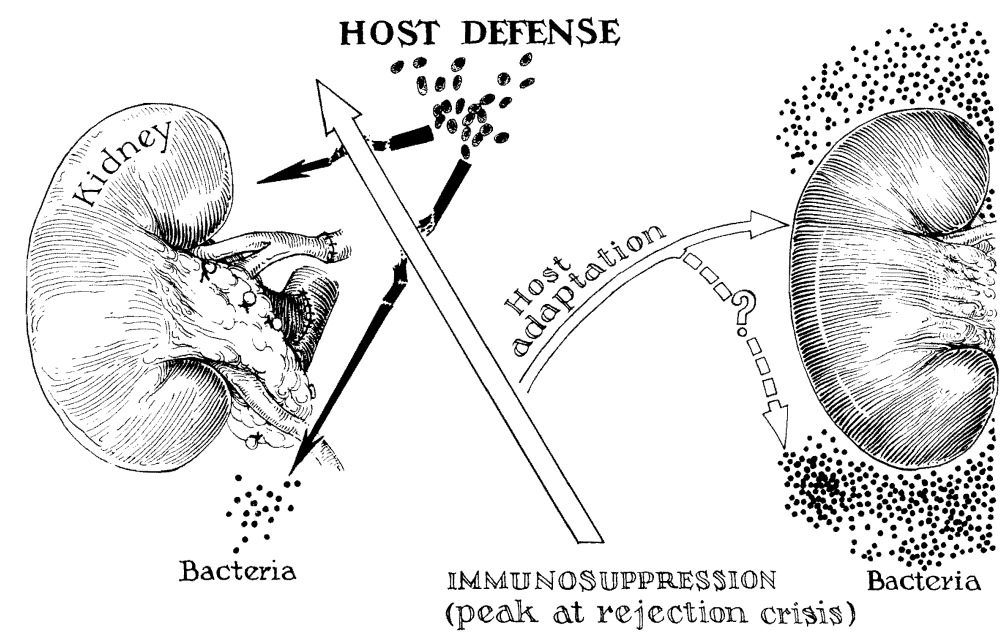


Bacterial Preumonitis. A variety of grampositive and gram-negative bacteria may cause pulmonary infections in immunosuppressed organ recipients. The organisms presumably gain entry to the lungs by inhalation or by descent from an upper respiratory tract infection. Because effective antibiotics are available for almost all of the common pyogenic organisms, accurate identification of the organism and determination of antibiotic sensitivities are essential for the successful treatment of bacterial pneumonitides. Because bacteremia frequently accompanies these infections, blood cultures may be useful for isolation of the causative microorganisms, but cultures of tracheal aspirates are usually sufficient for this purpose.

Despite the availability of specific antibiotics for these infections, bacterial pneumonitis has contributed significantly to the mortality following transplantation. In the early days of transplantation, there was a tendency to give too much azathioprine, and if bone marrow depression followed, bacterial pneumonitides were frequently fatal. ${ }^{30}$ In more recent years, the doses of either azathioprine or cyclophosphamide have been smaller, and granulocytopenia has been correspondingly rare. However, bacterial pneumonitis may still cause occasional deaths, particularly if it is complicated by abscess formation, empyema, coexisting devitalization of lung tissue, such as by pulmonary emboli, or the necrotizing vasculitis sometimes seen with Pseudomonas aeruginosa pneumonitis.

Fungal Pneumonitis. The avoidance of bone marrow depression has by no means eliminated infections by microorganisms of normally low pathogenicity for which truly effective and safe antibiotic therapy is not available. Fungal pneumonitides have been a common cause of late morbidity and mortality, ${ }^{30,85,87,88}$ the most frequently noted microorganisms in our series being Candida albicans and Aspergillus fumigalus, although in geographic areas in which Coccidioides and Histoplasma are endemic, infections with these fungi might be anticipated with greater frequency. Fungal infestation of the lungs may present as a diffuse pneumonitis or more commonly as a nodular lesion, which subsequently cavitates (Fig. 23). The diagnosis should be entertained in any recipient with a pulmonary infection in whom a bacterial etiology cannot be convincingly established or in whom the lesions are exacerbated by appropriate antibacterial therapy. A definitive diagnosis may sometimes be made from examination and cultures of tracheobronchial aspirates or of material obtained by the endobronchial brush technique of Fennessey. ${ }^{20} \mathrm{Nei}$ -

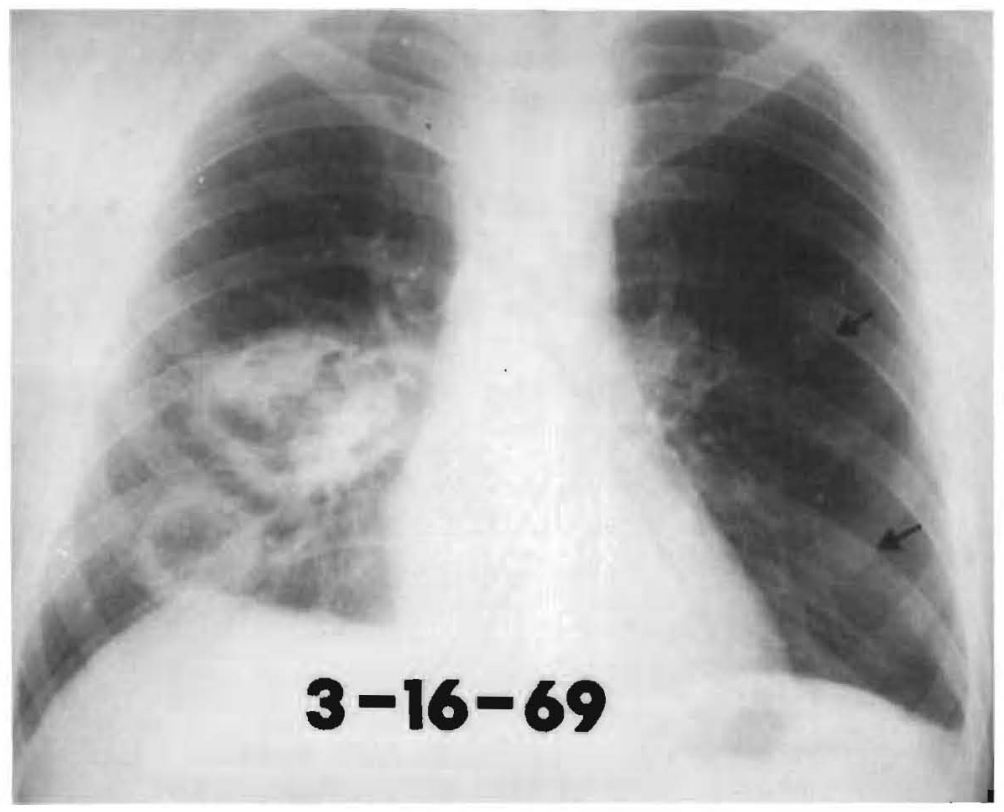

Figure 23 Chest $x$-ray of a patient with fatal Aspergillus fumigatus pneumonia. Note the cavitary lesions in the right lung field and the nodular lesions in the opposite lung (arrows). (From Pappas, G., et al.: Pulmonary Surgery in Immunosuppressed Patients. 1. Thorac. \& Cardiovasc. Surg. 59: $882,1970$. 